
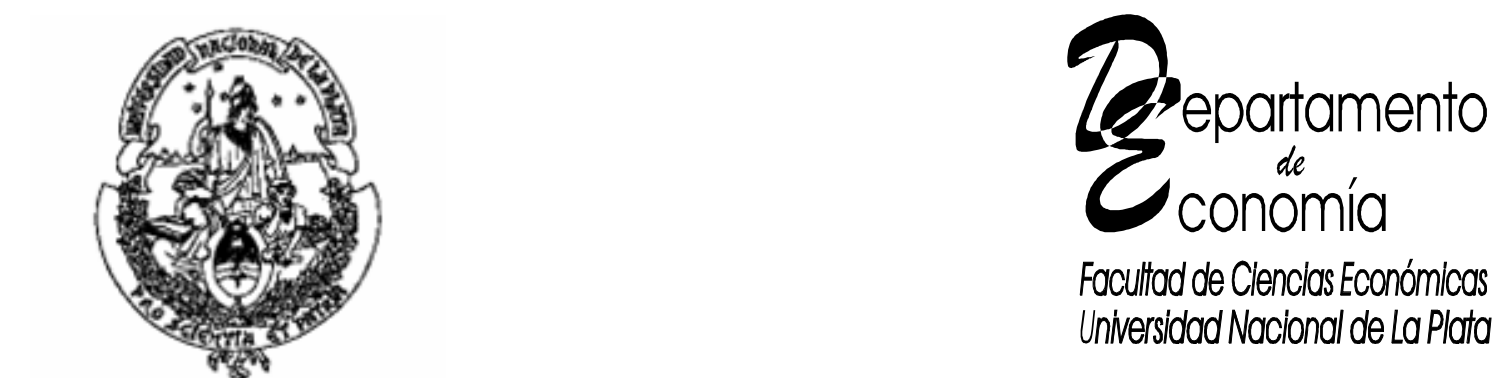

Facultad de Ciencias Económicas Universidad Nacional de La Plata

Universidad Nacional de La Plata

Individual H eterogeneity in the Returns to Schooling: Instrumental V ariables $Q$ uantile Regression using Twins $D$ ata O mar A rias, Kevin F. Hallock y Walter Sosa Escudero

Documento de Trabajo Nro. 16

Agosto 1999 


\title{
INDIVIDUAL HETEROGENEITY IN THE RETURNS TO SCHOOLING: INSTRUMENTAL VARIABLES QUANTILE REGRESSION USING TWINS DATA
}

\author{
Omar Arias \\ University of Illinois at Urbana-Champaign \\ Champaign, Illinois \\ Kevin F. Hallock \\ University of Illinois at Urbana-Champaign \\ Champaign, Illinois \\ Walter Sosa \\ Universidad Nacional de la Plata \\ La Plata, Argentina
}

March 29, 1999

We are grateful to David Card, Kenneth Chay, Bernd Fitzenberger, James Heckman, William Maloney, and particularly Roger Koenker for helpful discussions. We are also grateful to Orley Ashenfelter, Alan Krueger, and Cecilia Rouse for access to their data on twins. In addition, we appreciate the comments of seminar participants at the University of Illinois, the University of la Plata and the Instituto Ditella. The programs for the estimation and testing were written in S-plus and are available from the authors upon request. 


\title{
INDIVIDUAL HETEROGENEITY IN THE RETURNS TO SCHOOLING: INSTRUMENTAL VARIABLES QUANTILE REGRESSION USING TWINS DATA
}

\begin{abstract}
Considerable effort has been exercised recently in estimating mean returns to education while carefully considering biases arising from unmeasured ability and measurement error. Some of this work has also attempted to determine whether there are variations from the "mean" return to education across the population with mixed results. In this paper, we use recent extensions of instrumental variables techniques to quantile regression on a sample of twins to estimate an entire family of returns to education at different quantiles of the conditional distribution of wages while addressing simultaneity and measurement error biases. We test whether there is individual heterogeneity in returns to education against the alternative that there is a constant return for all workers. Our estimated model provides evidence of two sources of heterogeneity in returns to schooling. First, there is evidence of a differential effect by which more able individuals become better educated because they face lower marginal costs of schooling. Second, once this endogeneity bias is accounted for, our results provide evidence of the existence of actual heterogeneity in market returns to education consistent with a non-trivial interaction between schooling and unobserved abilities in the generation of earnings. The evidence suggests that higher ability individuals (those further to the right in the conditional distribution of wages) have higher returns to schooling but that returns vary significantly only along the lower quantiles to middle quantiles. In our final approach, the resulting estimated returns are never lower than 9 percent and can be as high as 13 percent at the top of the conditional distribution of wages, thus providing rather tight bounds on the true return to schooling. Our findings have meaningful implications for the design of educational policies.
\end{abstract}

JEL Classification: C14, I2, J24, J31

Key Words: Returns to Education, Human Capital, Heterogeneity, Quantile Treatment Effects, Instrumental Variables.

\author{
Omar Arias \\ Department of Economics \\ University of Illinois \\ 1206 South 6th Street \\ Champaign, IL 61820 \\ 217 333-0120 \\ o-arias@uiuc.edu
}

\author{
Kevin F. Hallock \\ Department of Economics \\ University of Illinois \\ 1206 South 6th Street \\ Champaign, IL 61820 \\ 217 333-4842 \\ hallock@uiuc.edu
}

\author{
Walter Sosa \\ Department of Economics \\ Universidad Nacional de \\ la Plata \\ La Plata, Argentina \\ 5415539983 \\ wsosa@feedback.net.ar
}




\section{Introduction}

The causal relation between education and earnings has been one of the most heavily and carefully explored subjects in empirical work in labor economics. The many empirical and theoretical difficulties associated with the analysis of such a relationship have been approached with a remarkable variety of econometric tools on diverse data sets. A well known problem that arises in these studies is that it is difficult to isolate the causal impact of additional education on earnings. One must be sure that what is claimed to be the return to additional schooling is not being distorted by the effect of other relevant but unobserved factors that may be related to schooling. More specifically, if unobserved "abilities" in the generation of earnings or family background factors are related to the level of schooling attained, ignoring such a link would lead to incorrect inferences regarding the causal effect of education.

There are several reasons why economists and policy makers are interested in obtaining accurate measures of the earnings premium associated with acquiring more education. From a "private" point of view, under certain conditions, it provides a measure of the "return" to investment in additional schooling. From a social standpoint, the return to education could give an indication of the relative scarcities of people with different levels of education and hence it may provide a guide for educational policies. ${ }^{1}$ (See Psacharopoulos and Ng, 1994 for a cost-benefit formulation).

In this paper we are interested in exploring whether people with different levels of "ability" obtain different returns to education. Specifically, we provide unique empirical evidence to address two of the important questions carefully laid out in Card (1995a): "what is the causal effect of education?" and "is there evidence of individual heterogeneity in returns to education?".

Our concept of "ability" refers to those marketable unobservable factors that make up an individual's initial endowment of human capital and translate into higher earnings. These may vary across families as well as individuals. This follows Griliches (1977) and differs from the view of ability as "IQ", for which measures can be constructed using test scores. Most studies estimate the mean return to education which may be interpreted as the return to additional schooling for an individual with mean ability. This is a sensible characterization when the return to education is constant across levels of (unobserved) ability so that any increase in schooling affects earnings of individuals that are observationally identical in the same way. In this case, ability and education do not interact in the generation of human capital; both factors have independent contributions to the accumulated stock.

Instead we take education and ability as two separate factors in the generation of human capital which interact in a non-trivial, unknown way. On the one hand, if we think that ability and

\footnotetext{
${ }^{1}$ The macro-evidence on the impact of more education on economic growth is controversial. See Pritchett (1997) for an interesting discussion of the issues.
} 
education are substitutes in the generation of human capital, then marginal returns to the accumulation of human capital are decreasing in ability and hence education contributes relatively more to low ability individuals. On the other hand, we might think that ability and education are complements in the generation of human capital, that is, education has an additional indirect effect on human capital and an indirect effect that comes through the interaction with ability that increases its otherwise constant contribution to earnings. We therefore want to investigate whether education induces a pure location shift in the distribution of earnings, or some more intricate change. In the language of the empirical literature on program evaluation, we are interested in whether the response to the treatment (education) varies across individuals. In this case, the mean return to education is only one summary of a richer pattern of ways that education affects people's earnings.

In order to explore this issue, we face several methodological and empirical limitations. First, we do not observe ability, so we cannot model its relationship with education explicitly by including additional regressors based on the former and estimate interaction effects with the later. ${ }^{2}$ Second, even though we can make some a priori conjectures about the relationship between ability and education, we do not want to impose unrealistic and unnecessary restrictions on this interaction. In the above examples, the return to education would be a monotonic function of the level of ability, but we see no reason to impose such a restriction. We want our empirical model to be exploratory and informative about the nature of this relationship. Third, education is not randomly assigned to individuals so we cannot treat the attained level of education as a predetermined variable. The optimal level of education may be determined endogenously as function of the level of ability and other factors such as family background. Fourth, it is well documented (e.g. Griliches, 1977, and Ashenfelter and Krueger, 1994) that the schooling variable is typically measured with error, which may introduce additional biases in conventional estimates that do not account for this possibility.

The interaction between ability and education studied in this paper has been directly or indirectly explored in some previous work but, as stressed in Card (1995a), there is little evidence in the empirical literature to support (or reject) the hypothesis of homogeneity in the returns to education. Ashenfelter and Rouse (1998) analyze an expanded version (three additional years) of the sample of genetically identical twins used in Ashenfelter and Krueger (1994). They exploit the presumed similarity of twins and the availability of multiple measures of schooling to explicitly model the link between family ability and education parametrically, while addressing the measurement error and endogeneity biases using standard panel data methods. They find some evidence of the existence of a negative relationship between ability and returns to education, suggesting that less able individuals 
benefit more from additional schooling. More recently, Conneely and Uusitalo (1998) investigate the question of heterogeneous returns in the context of a random coefficients model of wage determination. They use data on ability test scores and family background variables on a sample of Finnish men and parameterize potential heterogeneity in the mean return to education by interacting these factors with education. They find stronger evidence of variations in returns to education most of which, nevertheless, cannot be explained by observable individual heterogeneity.

We believe these fully parametric approaches impose strong restrictions on the structure of heterogeneity in returns to education. In this paper we use instrumental variables quantile regression methods on the recent sample of 858 genetically identical twins from Ashenfelter and Rouse (1998). Quantile regression methods allow us to estimate returns to schooling for individuals at different quantiles of the conditional distribution of earnings which we view as reflecting the distribution of unobservable ability. Unlike the above approaches which explicitly concentrate on the effect of education on the conditional mean of earnings and parameterize variations in returns through proxies for ability, quantile techniques allow us to freely characterize the effect of education on the whole conditional distribution of earnings.

Although he does not treat the ability-education interaction explicitly, Buchinsky's (1994) analysis of the U.S. wage structure, using Current Population Survey (CPS) data and censored quantile regression methods, shows that returns to education in the U.S. increase dramatically over the quantiles of the conditional distribution of wages. Mwabu and Schultz (1996) also use quantile methods on a sample of 3117 men for South Africa and obtain varying returns across quantiles that they interpret along the lines explored in this paper. Nevertheless, the results of these studies should be interpreted with caution since they do not handle the problems of measurement error or endogeneity bias. The finding of heterogeneous returns may simply reflect a variable ability-based endogeneity bias: more able individuals, facing lower marginal costs of schooling choose to acquire more education and appear to have higher marginal returns to education. See also Fitzenburger and Kurz (1998) for an interesting approach to studying earnings data using quantile regression and data from Germany and Machado and Mata (1999) who study wage inequality in Portugal.

The availability of twins data (with multiple measures of schooling) allows us to deal with the endogeneity of education arising from measurement error while indirectly controlling for any ability bias arising from "family effects". ${ }^{3}$ We also use testing procedures based on quantile regression statistics to formally test for the presence of heterogeneity in the returns to education. Our approach is

\footnotetext{
${ }^{2}$ It is well known that available measures such as IQ suffer from biases which reflect prior education and family background. Furthermore, these do not necessarily capture the type of "abilities" that enhance earnings potential.
} 
semiparametric in the sense that it imposes relatively weak parametric structure on the relationship between earnings and education. Minimal structure is imposed on the key relationship of interest: the interaction between education and ability in the generation of earnings.

As in all the other previous twins literature, our estimates rely crucially on the assumption that any absolute ability bias is due to unobservable family (inherited) factors. In a recent paper, Bound and Solon (1998) criticize the estimates of returns to education based on twins data questioning the validity of this assumption. If this assumption fails, our estimates can be thought to provide a whole family of bounds on the causal effect of education on earnings.

The paper is outlined as follows. In section 2, we specify a simple structural model of schooling choices closely based on Becker (1967), Card (1995a) and Ashenfelter and Rouse (1998). We extend the model by being less restrictive in the parameterization of heterogeneity. Section 3 briefly describes the data and outlines previous estimates of the mean return to schooling. In section 4 , we present the details of model specification and estimation, develop tests for heterogeneity in returns to schooling, and discuss the results. Section 5 discusses policy implications of our findings and concludes. In the appendix, we provide a brief discussion of quantile regression methods and the testing procedures used in the paper and highlight their usefulness for investigating heterogeneity.

\section{The Basic Model and its Interpretation in the Quantile Regression Context}

In this section we specify a simple structural model that highlights the main aspects of the problem. Following Ashenfelter and Rouse (1998) and Card (1995a) our model is based on the Becker (1967) model of investment in education with explicit focus on the following questions: 1) What is a sensible way to think about the link between ability and education? 2) Are returns to education homogeneous across the population? If not, how can we model the source of this heterogeneity and how can it be explored? 3) Why is quantile regression an appropriate tool to explore these types of effects which involve unobservable factors in a non-trivial way? 4) How does the availability of twins data allows us to deal with measurement error and simultaneity bias in the quantile regression framework?

\subsection{The Basic Model}

The starting point is the utility maximization problem of the $i$-th twin in family $\mathrm{j}$ :

$$
\max _{S_{i j}} U\left(Y_{i j}, S_{i j}\right)=\ln \left(y\left(S_{i j}, A_{j}, \varepsilon_{i j}\right)\right)-h_{j}\left(S_{i j}, r_{j}\right)
$$

\footnotetext{
${ }^{3}$ As explained in more detail below, the use of standard panel data methods in a quantile regression context introduces some complications.
} 
The first term consists of a human capital production function which receives as inputs education $\left(S_{i j}\right)$, an unobservable "ability" variable $\left(A_{j}\right)$, and a random twin specific disturbance $\left(\boldsymbol{\varepsilon}_{i j}\right)$ observed by the individual but not by the econometrician from an unspecified common continuous distribution function $f_{\varepsilon}$. This term reflects how education, ability and the idiosyncratic shock interact in the generation of earnings $\left(Y_{i j}\right)$. The second term measures the explicit and implicit (opportunity) costs of acquiring more education. It depends on education as well as family factors such as wealth or tastes for education summarized by $\left(r_{j}\right)$. We will think of $\left(A_{j}\right)$ as a measure of unobservable "family effects" that cause individuals from different families to earn different wages. These "family effects" could capture differences in family specific initial human capital, differences in the quality of schooling as well as differences in labor market connections across families. ${ }^{4}$ The individual random component captures factors such as individual specific ability and risk taking that allow otherwise identical individuals from the same family to earn different wages.

The schooling decision of an individual in the $j$-th family depends at the margin on the balance of the marginal benefits and costs from additional schooling given his or her endowment of ability and family background. If utility is globally concave with respect to $\left(S_{i j}\right)$, there will be a unique level of education $S_{i j}^{*}=S_{j}\left(A_{j}, r_{j}, \varepsilon_{i j}\right)$ that solves the utility maximization problem. Thus, optimal schooling choices will potentially differ both among individuals of different families due to "family effects" and between twins from the same family due to the idiosyncratic disturbance in the earnings function. This is precisely the well known endogeneity of ability bias that has historically haunted estimates of the returns to schooling. The acute problems that the potential correlation between $\left(A_{j}, r_{j}, \varepsilon_{i j}\right)$ and the observed choices of $\left(S_{i j}\right)$ pose to estimation of even the simplest linear empirical earnings functions were lucidly discussed by Griliches $(1977,1979)$.

The advantage of using data on earnings and education from a sample of twins to estimate the returns to schooling comes from exploiting the common components of the unobservable ability variable across twins. Let $v_{i j}=\gamma A_{j}+\varepsilon_{i j}$ which corresponds to our concept of "ability". A simple specification that allows us to highlight the important issues is

$$
U\left(Y_{i j}, S_{i j}\right)=\beta_{0} S_{i j}+\phi\left(S_{i j}, v_{i j}\right)+v_{i j}-\left[-r_{j} S_{i j}-0.5 c S_{i j}^{2}\right]
$$

where $e^{\beta_{0} S_{i j}+\phi\left(S_{i j}, v_{i j}\right)+v_{i j}}$ represents the earnings function and $e^{-r_{j} S_{i j}-0.5 c S_{i j}^{2}}$ for the anti-log of the cost function. ${ }^{5}$ In this case the marginal condition for a maximum solution to (1) is: ${ }^{6}$

\footnotetext{
${ }^{4}$ Since twins tend to attend the same school, differences in the quality of schooling are only relevant across families.

${ }^{5}$ This is an extension of Rosen (1973).

${ }^{6}$ Sufficient conditions for (2) to define a maximum are that $M B_{i j}>0, M C_{i j}>0$ and
} 


$$
M B_{i j} \equiv \beta_{i j} \equiv \beta_{0}+\phi_{S_{i j}}=M C_{i j} \equiv r_{j}+c S_{i j}
$$

where $\phi_{S_{i j}}$ denotes the derivative of $\phi$ with respect to $S_{i j}$.

Following Becker (1967), $\beta_{i j}$ is interpreted as the return to schooling, which at this point may depend on the level of education and unobservable ability. The function $\phi$ governs the process by which ability affects the rate at which human capital is accumulated. Thus, assuming differentiability, in (2) at the optimal level of schooling we have that:

$$
\frac{\partial \ln \left(Y_{i j}\right)}{\partial S_{i j} \partial v_{i j}}=\frac{\partial M B_{i j}}{\partial v_{i j}}=\phi_{S_{i j}, v_{i j}}
$$

where $\phi_{S, v}$ denotes the cross-partial second derivative of $\mathrm{U}$ with respect to $S_{i j}$ and $v_{i j}$ and captures how ability affects the return to education. As long as $\phi_{S, v} \neq 0$ the return to education will not be constant across individuals (of the same education level). Differing abilities alter returns so that there exists a family of returns to education. This is precisely what we mean by heterogeneity in the returns to education. Note that the standard specification and estimation of Mincer equations assumes $\phi_{S, v}=$ 0 implicitly which implies that education and ability are "perfect substitutes" in the production of human capital. If $\phi_{S, v}>0$ ability enhances the productivity gains of acquiring an additional year of education, while if $\phi_{S, v}<0$ high ability individuals face lower returns to investment in education. Both cases are possible since we do not need to require $\phi_{S}$ to be monotonic in $v_{i j}$. Similarly, for $c>0$, marginal cost is increasing in education and depends on $r_{j}$ which implies variations in the rate at which individuals of the same family substitute schooling for future earnings. Since higher ability parents will tend to have higher earnings and acquire more education, these differences may in turn reflect differences in the wealth or tastes for education across families. We expect $A_{j}$ is negatively correlated with $r_{j}$ to capture the intuitive notion that individuals from more able families face lower disutilities of schooling.

As discussed by Ashenfelter and Rouse (1998), a crucial condition to identify the return to schooling from within-family variation in schooling levels is that any differences in schooling between twins of the same family are due to optimization or measurement errors that are uncorrelated with the earnings disturbance. That is, we need to assume that:

$$
S_{i j}^{*}=S_{j}^{*}+u_{i j}
$$

where the $u_{i j}$ are $i i d$ errors over $\mathrm{i}$ and $\mathrm{j}$ from an unspecified continuous distribution function $f_{u}$, and are independent of the $\varepsilon_{i j}$ and true schooling levels. This amounts to assuming that any within twins difference in the marginal benefit from schooling do not affect their optimal schooling choices. Note

$$
0<\frac{\partial M C_{i j}}{\partial S_{i j}}>\frac{\partial M B_{i j}}{\partial S_{i j}} \text {, that is: } \beta>0, c>\phi_{s s} \text { and } c, r_{j}>0 \text {. }
$$


that twins from different families can still choose different education levels due to differences in family ability. ${ }^{7}$ Recently Bound and Solon (1998) have raised questions on the plausibility of this assumption. Nevertheless, using the same data we use in this work, Ashenfelter and Rouse (1998) carried out a variety of tests which provide evidence consistent with the hypothesis that schooling choices among twins are uncorrelated with unobservable determinants of earnings. ${ }^{8}$

Note that (3) implies that differences in observed schooling levels in the population arise from two sources. First, individuals may have differing returns to schooling (due to differing $A_{j} \mathrm{~s}$ ). Second, individuals may have different marginal rates of substitution between schooling and future earnings $\left(r_{j}\right)$ due to differences in the implicit marginal costs of schooling. Thus, for the utility specification considered we have that at $S_{i j}^{*}$ :

$$
\frac{\partial^{2} U_{i j}}{\partial S_{i j} \partial A_{j}}=\phi_{S, A}-\frac{\partial r_{j}}{\partial A_{j}}
$$

which determines the rate at which an individual of the same family can substitute ability and education in the generation of utility. When (5) is negative the marginal rate of substitution between ability and education is decreasing with the level of ability: the same amount of schooling substitutes less ability as an individual becomes gradually more educated. The opposite is true if it is positive. Since we expect the correlation between $A_{j}$ and $r_{j}$ to be negative, then in the case that $\phi_{S, A}>0$ we have that both effects work in the direction of enhancing the ability-based endogeneity bias by which more able individuals are the more educated.

\subsection{The Empirical Framework}

Integrating $M B_{i j}$ over $S_{i j}$ we obtain the log-linear human capital production function for which we adopt the following empirical specification:

$$
\ln \left(Y_{i j}\right)=\alpha F_{j}+\lambda X_{i j}+\beta_{o} S_{i j}+\phi\left(S_{i j}, v_{i j}\right)+v_{i j}
$$

often called the Mincer (1974) equation. We denote observed family specific variables (age (for twins), race), $F_{j} . X_{i j}$ stands for observed individual specific characteristics other than education such as union participation and marital status, and $\alpha, \lambda, \gamma, \beta$ are the corresponding coefficients. This equation together with (4) determine the joint distribution of earnings and education.

\footnotetext{
${ }^{7}$ This implies that individuals have better information than the econometrician but that this is still imperfect.

${ }^{8}$ For instance, they report that about $60 \%$ of the variability in schooling choices is due to differences across families, and that potential non-genetic differences in ability between twins (such as birth order) are not significantly correlated with earnings. In addition, when asked why they have attained different schooling only $11 \%$ of the twins reported reasons that might be interpreted as reflecting within twins ability differences.
} 
Our empirical model aims to estimate the returns to schooling from data on wages and education from a sample of twins while accounting for four features of empirical measurements from this distribution: i) the stylized log-linear relationship between observed wages and education, ${ }^{9}$ ii) heterogeneity in the distribution of earnings conditional on education, iii) the endogeneity of observed education levels due to unobservable ability, and iv) measurement error in observed schooling choices.

First note that the presence of $\phi$ introduces a potential non-linearity in the above log-linear Mincer equation. Nevertheless, because of the positive correlation between $\beta_{i j}$ and education, equation (6) is not necessarily inconsistent with a linear relationship between log wages and education. For instance, as pointed out by Card (1995a), if for a given level of ability, wages are a concave function of education, the data for the population as a whole could still trace out a convex relationship between wages and education. ${ }^{10}$ In order to keep consistency with the documented log-linearity of wages and education we shall assume that $\phi_{S, A}$ is independent of education. We discuss the issues involved in (ii)(iv) below.

\subsubsection{Quantile Regression and Unobserved Heterogeneity.}

Provisionally, let us ignore the endogeneity ability bias and measurement error in education for now, ie., assume that $S_{i j}$ is independent of family effects and can be treated as exogenous. The optimal schooling model outlined above implies that unobserved ability induces heterogeneity in the joint distribution of earnings and schooling. Letting $Z=\left(F_{j}, X_{i j}\right)$, we see that OLS on (6) gives a measure of $\partial E\left(\ln \left(Y_{i j}\right)\left(Z_{i j}, S_{i j}\right)\right) / \partial S_{i j}=\beta_{o}+\delta \bar{A}$ : the return to education for an individual with mean ability as pointed out by Card (1995a). In this case the labor market cannot yet be well characterized by a single rate of return to education. Ashenfelter and Rouse (1998) focused on the conditional mean of the distribution of wages to obtain different estimates of $\beta_{i j}$ for the case that $\phi_{i j}=\delta A_{j} S_{i j}$ so that heterogeneity takes the simple linear heteroskedastic form:

$$
\partial \ln \left(Y_{i j}\right) / \partial S_{i j} \equiv \beta_{j}=\beta_{o}+\delta A_{j}
$$

Here $\delta$ captures the effect of ability on the return to education (ie., (3)). They estimate $\delta$ by including as an additional regressor an interaction term between education and the average education of a pair of twins from family $j$ which from (4) can be taken as a proxy for ability in that family. A negative $\delta$ means that returns to education are lower for high ability individuals, which in our model is interpreted as a decreasing marginal rate of substitution between ability and education. In this case low ability individuals benefit more from additional education. An analogous interpretation holds for positive

\footnotetext{
${ }^{9}$ See, for example, Heckman and Polachek (1974) and Park (1994).
} 
$\delta$. The drawback of this approach is that the resulting estimate of the heterogeneity parameter (and thus of the $\beta_{\mathrm{j}} \mathrm{s}$ ) relies on a full parameterization of the interaction between education and unobserved ability $A_{j}$. The same limitation applies to the recent attempt of Conneely and Uusitalo (1998) of estimating heterogeneous returns to education based on conditional mean wage functions. The approach makes it very difficult to separately identify the effect of ability on the marginal benefit of schooling, as reflected in estimates of the interaction coefficient that are in general statistically insignificant. We want to be able to characterize the family of returns to education without making such restrictive parametric assumptions.

The regression quantiles of Koenker and Bassett (1978) provide a more general approach to characterizing the effect of education on different percentiles of the conditional distribution of wages, thus allowing us to explore and estimate heterogeneity in the returns to schooling. Specifically, a zero conditional quantile restriction on the error $v_{i j}$ implies that the effect of education on the $\tau$-th quantile of $Y_{i j}$ conditional on the observables in (6) is: ${ }^{11}$

$$
\frac{\partial Q_{\tau}\left(Y_{i j} \mid Z_{i j}, S_{i j}\right)}{\partial S_{i j}} \equiv \beta_{\tau}=\beta_{o}+\frac{\partial Q_{\tau}\left(\phi\left(S_{i j}, v_{i j}\right) \mid Z_{i j}, S_{i j}\right)}{\partial S_{i j}}=\beta_{o}+G_{v}^{-1}\left(\tau \mid Z_{i j}, S_{i j}\right)
$$

where $G_{v}$ is some transformation of the distribution function of abilities in the population since we have assumed that the marginal return to education is independent of education. Thus, by estimating quantile regressions for different values of $\tau$ one can obtain consistent estimates of the whole family of returns to education functions reflecting the distribution of abilities across individuals (Note that in the absence of heterogeneity, $\beta_{0}=\beta_{\tau}$ for all $\tau$. The interaction between education and ability can then be explored by comparing $\beta(\tau)$ s at different quantiles $\tau_{k}$ and $\tau_{j}$, for $i \neq k$. Moreover, a robust test of the hypothesis of heterogeneity $\beta_{k} \neq \beta$ for some $k$ ) can be based on a test of whether the estimated coefficients for the returns to education differ across quantiles. That is, using the test for heteroskedasticity proposed by Koenker and Bassett (1982). Unlike the prior approaches, this does not require strong parametric restrictions on the type of interaction between ability and education.

As indicated previously, the findings of heterogeneous returns by Buchinsky (1994) and Mwabu and Schultz (1996) based on quantile wage equations come close to such a characterization. Nevertheless, this work does not address the problems of endogeneity bias and measurement error in education, and does not structurally model the source of heterogeneity. Since (3) implies that in general $Q_{\tau}\left(v_{i j} \mid S_{i j}\right) \neq 0$, quantile regression on a Mincer equation like (6) would yield inconsistent estimates of the family of returns to education just as OLS fails to deliver a consistent estimate for the mean return.

\footnotetext{
${ }^{10}$ Specifically, he considers the case where $\phi=b_{j} S_{i h}-0.5 k_{1} S_{i j}^{2}$ with $b_{j}$ reflecting variations in ability.

${ }^{11}$ Note that $Q_{\tau}(Y)=Q_{\tau}(\ln (Y))$ because of the equivariance of quantiles to monotonic transformations.
} 
In fact, varying returns to education can be a result of an endogeneity bias that varies across quantiles of the conditional distribution of wages rather than evidence of actual ability-based differences in the market marginal returns to education. We now discuss how the data on twins allow us to more carefully uncover the evidence for "true" heterogeneity in the returns to education while addressing both the simultaneity and measurement error biases.

\subsubsection{The Endogeneity of Schooling}

In our model, individuals from higher ability families $\left(A_{j}\right)$ become better educated due to lower marginal costs of schooling. As noted before, if ability and schooling are "complements" in the generation of earnings, then the higher returns to education for the more able enhance this endogeneity bias in schooling. In the previous literature on estimation of the returns to education using twins data this problem has been addressed in two ways. One approach is to treat $A_{j}$ as an unobserved random family effect and focus the interest on obtaining unbiased estimates of the structural coefficients $\beta_{\mathrm{j}}$ measuring the returns to education. This can be accomplished by directly estimating a "fixed effects model" based on the (within) differenced equation corresponding to (6) for each pair of twins across

families. Since (2) and (6) imply that $E\left(\xi_{j} \mid \Delta S_{i j}, \Delta X_{i j}\right)=0$ where $\Delta$ is the difference operator and $\xi_{j}=\varepsilon_{l j}-\varepsilon_{2 j}$, OLS on differenced data yields consistent estimates of the mean return to education. This is the strategy adopted by Ashenfelter and Krueger (1994) and Ashenfelter and Rouse (1998) to deal with the ability bias in the OLS context.

One might naïvely consider quantile regression on a differenced Mincer equation since then $Q_{\tau}\left(\Delta \xi_{i j} \mid \Delta S_{i j}\right)=0$. Nevertheless, there is a fundamental drawback with this approach. Although differencing in the least squares context can be shown to be equivalent to a fixed effects estimator, in the context of quantile regression, this is not the case. Estimates of quantile regression education coefficients from a differenced equation would reflect the effect of education on the quantiles of the conditional distribution of the difference in wages between a pair of twins across families, rather than the effect on the difference in the quantiles of the corresponding conditional wage distributions. Since quantiles of the sum of two random variables are not equal to the sum of the quantiles of each random variable at a given $\tau_{j}$, when differencing in quantile regression, the order of the individuals matters. Thus, it is not possible to recover the estimates obtained using data on levels on an equation like (6) from the estimates of quantile regressions on differenced data. Moreover, the natural attempt to estimate the fixed effects model including family specific dummies is also futile in this case given the unavoidable ambiguity surrounding the identification of the fixed effects at any given quantile with only two observations per family. 
An alternative approach is to try to parameterize and estimate the endogeneity (omitted ability variable) bias explicitly including some proxy for unobserved ability as an additional regressor when estimating equation (6). As long as the proxy can account for most of the endogeneity bias, this approach also allows us to obtain consistent estimates of the returns to education. Ashenfelter and Krueger (1994) and Ashenfelter and Rouse (1998) also provide such estimates of the returns to education and the resulting endogeneity bias (to which they refer as a "selection effect"). The model of optimal schooling choices outlined in section 2 suggests that we use measures of the education of a twin's sibling, the average education of the twins, or father's education as an additional regressor to control for any "family" effect that affect the absolute level of earnings. This is the approach we use in our empirical work and we label the resulting specifications as "family effects" models. The coefficients on these variables provides us with alternative quantile specific estimates of the ability bias in the estimates of returns to schooling.

\subsubsection{Measurement Error in Education}

The information contained in the available twins data provides an interesting way to address the problem of measurement error in reported schooling which can arise because of the recall errors common in survey data. This is specially important since from the work of Griliches (1977) it is well known that the attempt to control for any absolute ability bias using family education variables to proxy for family effects exacerbates already existing biases.

As reported in Ashenfelter and Krueger (1994) and Ashenfelter and Rouse (1998), twins are asked to report on the education level of their sibling and of their parents. Letting $S_{i j}^{k}$ be twin $k$ 's report of the $n$-th family member, we can expect such cross-reports to satisfy (3) so that:

$$
S_{n j}^{k}=S_{n j}^{*}+u_{n j}^{k}
$$

where $u_{n j}^{k}$ denotes iid measurement errors over i $\mathrm{n}$ and $\mathrm{j}$.

These cross-reports of each family member's education can then be employed as instruments using recent extensions of instrumental variable methods to quantile regression (see the appendix). Moreover, the availability of multiple reports allows us to relax the classical assumption of uncorrelated measurement errors in the own-reports of a twin. This can occur if a twin that overreports his own education level is also more likely to overreport the education level of his sibling and of his parents. Following Ashenfelter and Krueger (1994) and Ashenfelter and Rouse (1998), we also estimate quantile regression models that assume correlated measurement errors in education.

\section{Data Description and Previous "Mean" Results}


The data used in this paper were collected over a span of five years at four meetings (August of 1991, 1992, 1993, and 1995) of the Annual Twins Festival in Twinsburg Ohio. Many of the questions are similar to questions asked in the Current Population Survey (CPS) with some twinsspecific questions added. As Ashenfelter and Krueger (1994) and Ashenfelter and Rouse (1998) show, the mean characteristics of the sample are quite similar to the population at large. Sample characteristics are reported in Table 1. The sample we use has, on average, more years of education, higher income, and is more likely to be female and white than the population at large. Ashenfelter and Krueger (1994) also note these similarities and differences.

Table 2 reports regression results employing econometric specifications similar to Ashenfelter and Krueger (1994), Ashenfelter and Rouse (1998) and Rouse (1997) who focused on estimating the mean return to education. We briefly present these results for three reasons. First to highlight (as in the previous literature) the importance of considering both ability and measurement error biases in estimating mean returns to education. Secondly to document the mean return to education using these specific data. Finally, Table 2 provides a summary of the data and specifications that will be extended to the quantile regression framework below.

The first five columns of Table 2 estimate very simple empirical earnings equations. Column 1 of Table 2, reports the simple least squares regression of the log of earnings on age, (age $)^{2}$, a gender indicator equal to 1 if the individual is female and an indicator equal to 1 if the respondent is white. This model is estimated using all 858 respondents for which we have complete data. In column 2 we have included additional controls for marital status, union coverage and tenure. As usual, there is a positive seniority profile, and the female indicator is large and negative. The white indicator is also negative (an anomalous result also found in Ashenfelter and Krueger, 1994, Ashenfelter and Rouse, 1998, and Rouse, 1997) but is not statistically different from zero. The return to education estimated in column (1) is $10.8 \%$. As we have stated earlier and as is well documented in Griliches (1977) and Ashenfelter and Krueger (1994), this estimate is potentially upward biased due to unobserved ability and downward biased due to measurement error. A great deal of effort has been focused on determining the "true" return to education after accounting for these biases. Card (1995a) provides an important and interesting summary of a set of papers that find that simple least squares estimates seem to be downward biased ${ }^{12}$.

The other columns in table 2 present the results of estimating additional, yet similar, specifications that address these ability and measurement error biases. Column 3 presents the estimates for a model that tries to control for endogeneity bias using father's education as a proxy for 
family specific ability. We can see that this reduces the return to education from $12 \%$ (column 2) to $11.4 \%$ and that the coefficient on father's education is significant, thus consistent with an upward ability bias. On the other hand, comparison of the OLS and IV estimates reported in columns 3 and 5 suggest the presence of a slight downward bias in the mean return due to measurement error in education. Instrumental variables results from a specification similar to column 5 that includes father's education (not reported) are also consistent with this view.

Columns 6-9 estimate models where the data are "differenced." Each unit of observation is created by subtracting the given variable from his or her twin's. Column 6 , then, is simply the difference in $\log$ twins wage on the difference in reported education for the twins. Column 8 contains our mean estimate that is most closely related to Ashenfelter and Krueger's (1994) final estimate (reprinted as column 9). This is the differenced model using instrumental variables where the instrument is the first twin's report of the second twin's education minus the second twin's report of the first's. Our resulting estimate of the return to education $11.9 \%$ is not unlike the least squares estimate of $10.8 \%$ but is considerably lower than Ashenfelter and Krueger's (1994) similarly specified estimate of 16.7\%. Rouse (1997) using the same four years of data that we use (Ashenfelter and Krueger, 1994 use only one year) points out that "Unlike the results in Ashenfelter and Krueger, I find that the withintwin regression estimate of the effect of schooling on the log wage is smaller than the cross-sectional estimate, implying a small upward bias in the cross-sectional estimate." She further notes, however, that her results and those of Ashenfelter and Krueger are not statistically different and suggests that the difference is perhaps due to sampling error.

In the next section we turn attention away from estimating the mean return toward estimating and testing the implications of our simple theoretical model of heterogeneity in the returns to schooling.

\section{Estimation Details and Empirical Results}

This section outlines in more detail the framework we use to develop our empirical models and formal tests for heterogeneity in the returns to education under the presence of endogeneity and measurement error biases. In Sections 4.1 to 4.5 we detail the specifications we use, describe the empirical results and the strategies for testing equality in the returns to schooling across various quantiles. See the Appendix for a brief technical description of the methods used.

The main focus of this paper is on estimating and testing for heterogeneity in returns to schooling across quantiles of the conditional wage distribution while addressing endogeneity and measurement error biases. To this end, we will consider four empirical models: 1) the levels model

\footnotetext{
${ }^{12}$ These studies include Angrist and Newey (1991), Angrist and Krueger (1991), Angrist and Krueger (1992), Butcher and Case (1994), Card (1995b), and Kane and Rouse (1995).
} 
without instrumental variables, 2) the levels model with instrumental variables, 3) the family effects model without instrumental variables, and 4) family effects model with instrumental variables. The ideas behind these models roughly follow the empirical work in the recent literature on twins (Ashenfelter and Krueger, 1994, Ashenfelter and Rouse, 1998, and Rouse, 1997) replicated in Table 2.

\subsection{Levels Model Without Instrumental Variables}

Figure 1 presents the quantile regression estimates of the returns to education for the levels model without instrumental variables. The $\beta(\tau)$ 's for the 5th to 95th quantiles are plotted in increments of 0.05 and the figure is separated into five sub-figures according to the covariates included in the estimation. In addition to controlling for education these plots control for A) education only, B) age, race, and gender only, C) ("all” but tenure) controls for age, race, gender, married, and union, D) ("all" but union) controls for age, race, gender, married, and tenure, and E) controls for age, race, marital status, union, and tenure.

We focus our attention on the specification that includes all covariates (Figure 1E). The actual returns for each of the 19 quantiles are also reported in Table 3A, Panel A with 90\% confidence bounds for this specification (the confidence bounds are also reported in the figures). Recall that homogeneity in returns would imply that the figures are flat. A cursory examination of the figures suggests the presence of heterogeneity in the returns to education. The returns are, in general, increasing for higher quantiles of the conditional distribution of wages. In particular, the median return to education from Table $3 \mathrm{~A}$, panel $\mathrm{A}$ is $13.1 \%$ (compared to the mean return of $12 \%$ reported in column 2 of Table 2). However there is a striking increase in the return from the low quantiles to higher quantiles going from $9.2 \%$ at the 0.05 quantile to $13.1 \%$ at the median, after which the returns essentially remain constant. Note also that the magnitude and the pattern of the estimates of the returns to education remain remarkably similar across specifications (see figure 1). Also note that the confidence bands in each figure within Figure 1 don't include $\beta_{\tau}=\beta_{0}$ for any $\beta_{0}$. That is, for this simple specification, the returns do not appear to be homogenous.

We test whether the observed differences are statistically significant across quantiles and report the results of such tests in Table 3B, panel A. The tests confirm the visual impression. The tests of equality of returns between the low quantiles and the middle quantiles, and between the low and high quantiles reject the hypothesis of homogeneous returns at 1-2\% significance levels. For example, there is a statistically significant difference between the returns at the 0.10 and 0.50 quantiles ( $t$ statistic $=5.82, \mathrm{p}$-value $=0.016)$. Note, however, that the differences between the middle and higher quantiles are not significant. Another way to see this is that Figure 1 flattens out in the right tail. These findings are consistent with the existence of a variable complementary relationship between ability and 
education in the generation of earnings for those in the lower tail of the conditional distribution of wages (i.e., the low ability), while for the upper tail marginal returns to education are higher but remain constant.

\subsection{Levels Model with Instrumental Variables}

Of course, the above results are still subject to the two main criticisms described by and controlled for in Ashenfelter and Krueger (1994) and Ashenfelter and Rouse (1998) investigating the mean return to education. We take the first step toward addressing these problems by estimating the levels model using instrumental variables for the education variable to alleviate the measurement error problem. We follow the previous literature and use twins \#2's report of twin \#1's own education (and vice versa) as an instrument. These results are reported in Figure 2 which is arranged like Figure 1 in that we report results for five different sets of covariates. Again, we have reported the returns to education for the 19 quantiles 0.05 to 0.95 in Table 3A panel B with $90 \%$ confidence bounds for the specification including all covariates.

The same general conclusions drawn from Figure 1 may be drawn from Figure 2. In particular, failure to address the measurement error in education in the levels model does not seem to create a significant downward bias in the estimated returns to schooling. After controlling for measurement error in the levels model, we can still see evidence of heterogeneity in returns to education with increasing returns at higher quantiles. Notice, however, that the standard error bands are somewhat wider in the instrumental variables case so even if there are small differences, they are unlikely to be significant.

We report tests of significance in the levels model with instrumental variables in Table 3B, panel B. Here the results are largely consistent with those in the levels model without instruments, supporting the visual impression of heterogeneous returns except that the tests cannot reject the hypothesis of equality of returns between extreme quantiles due to higher standard errors of these estimates. This might suggest that instrumenting affects the "true" schooling signal in own reported education more sensibly for those at the tails of the conditional wage distribution. Overall, the findings suggest that the bias that arises from measurement error in education in the levels models is not very important. In the absence of endogenous ability bias, the estimates from the previous levels models would provide relatively accurate measures of the family of returns to schooling.

\subsection{Family Effects Model Without Instrumental Variables}

This section and the one that follows repeats the analysis of sections 4.1 and 4.2 with the additional innovation that we attempt to control for the well-known ability bias problem. As we stated 
in Section 2.2 above, the implementation of a quantile regression analogue of estimating an OLS fixed effect or differenced model is problematic. Instead, in our quantile regression equivalent of a fixed effects model we use the father's level of education and the sibling's education as proxies for the family effect. We only report the results for the former. ${ }^{13}$ Essentially, we are re-doing the analysis reported in Figures 1 and 2 and Tables 3A and 3B with the additional covariate which is the father's schooling level. Note that even though we follow Ashenfelter and Rouse (1998) in the parameterization of the endogeneity bias in this way, we do not parameterize the impact of the interaction between ability and education on earnings. The novelty of our approach lies precisely in the use of quantile regression techniques to explore this relationship based on the quantiles of wage residuals that we interpret as capturing unobservable ability to generate earnings.

Figure 3 reports the results. Table 4A, panel A reports the returns to education for 19 quantiles 0.05 to 0.95 with $90 \%$ confidence bounds for the specification including all covariates. Clearly, including the family effects has a substantial effect on the estimated returns. In general, the lines in Figure 3 are lower than the corresponding ones in Figure 1, particularly at higher quantiles. This is consistent with our expectation that part of the return to education is absorbed by the family effect thus reflecting a positive endogeneity bias. This can be seen in the Appendix Figure which plots the coefficient on father's education and sibling's education for the 19 quantiles. The estimates of the endogeneity bias across different quantiles are in general increasing, though the precision of these estimates is poor. Note that the sibling's family effects models yield a slightly higher estimate of the endogeneity bias, but the precision of the estimates is much poorer. This suggests that the findings of Buchinsky (1994) of higher returns to education at higher quantiles and to a lesser extent those of Mwabu and Schultz (1996) reflect in part a differential endogeneity bias in schooling choices of individuals with different abilities rather than "true" differences in the marginal returns to education for those in the upper tail of the conditional wage distribution.

Nevertheless, it is quite clear from Figure 3 that in each specification, though the quantile curves of the estimated returns are flatter than in Figure 1, they are still generally increasing. These patterns remain essentially intact when using sibling's education as a proxy for family ability. Therefore, although differences across quantiles are, no doubt, less significant, there still appears to be some heterogeneity in the returns to education. This is confirmed by the tests we report in Table 4B panel A which indicate rejection of the hypothesis of homogeneous returns in the middle quantiles. Despite the apparent substantial differences in the estimated returns between extreme quantiles, poor precision as reflected by the wider confidence bounds leads to insignificance test statistics.

\footnotetext{
${ }^{13}$ We also estimated specifications using the average education level of the twins as a proxy for family ability. As expected this resulted in somewhat higher estimates of the ability bias but the precision of these and the
} 


\subsection{Family Effects Model With Instrumental Variables}

The problem with the estimates from the previous Section is that by including measures of education to control for family effects, the potential bias arising from measurement error in schooling levels is now aggravated since the cross-correlation between education levels (which is 0.75 among siblings) washes away some of the "true" schooling signal in own-reported education levels. In this Section we report the results of our best attempt to control for both the ability and the measurement errors biases. This is the direct extension of section 4.2 except that we now use twin \#2's reports of father's education and of twin \#1's own report to instrument for potential measurement error in twin \#1's report of father's education and twin \#1's reported education, respectively (and vice versa). In the case of sibling's education we also estimated models that allow for correlation in the measurement errors of a twins' reports. Again we only report the results for the models using father's education since these results were very similar, except for the poorer precision of the estimates from the sibling's education models. In Figure 4, which we call the "family effects" models with instrumental variables, the returns are somewhat sporadic. Note also that the confidence bands are wider, specially at the extreme quantiles.

We report the actual returns and confidence intervals for the model with all variables in table 4, Panel B. A comparison with the non IV estimates of the analogous family effect model indicates that the IV estimates are somewhat larger (consistent with a downward bias due to measurement error) but only in the lower tail of the distribution of wage residuals. Considering the wider confidence bounds on the IV estimates these differences are hardly significant. Moreover, although the family effect model with instruments (Figure 4E) still suggests some mild heterogeneity in the returns to education with higher returns at higher quantiles, the estimates are somewhat imprecise. In fact, when we test (Table 4B, panel B) for differences across quantiles, only in the middle quantiles do we find some evidence of heterogeneity in the returns ( $\mathrm{p}$-values between 5-10\%). Once again it appears that the attempts to deal with both the endogeneity bias and measurement error washes away most of the "true" schooling signal of own reported education at the tails of the conditional wage distribution leading to less precise estimates. From the Appendix Figures we can see in fact that the estimates of the family effects based on both father's education and sibling's education are rather imprecise in the instrumental variable models.

\subsection{Do the Endogeneity and Measurement Error Biases Matter? Are Returns Heterogeneous?}

coefficients on education was much poorer. 
We now briefly summarize what we have learned from our empirical models that attempt to document the existence of heterogeneity in the returns to schooling while dealing with the two well known sources of biases. The results are summarized in Figure 5 which decomposes the differences in the estimated returns to education obtained from the "all" covariates specification across our four empirical models into the endogeneity bias and measurement error components. ${ }^{14}$ Turning first to the measurement error problem, we see that comparison of the levels model non-IV vs. IV (see Figure 5A) and father's education model non-IV vs. IV (see Figure 5C) both reveal that the IV estimates seem to be slightly higher than the non-IV case in the left tail, consistent with a slight downward bias due to measurement error. The IV estimates actually appear to be lower than the non-IV at the high quantiles (0.8-0.9) but this probably reflects the effect of noisier estimates at the tails. ${ }^{15}$ So, one can conclude that the evidence suggests that failure to account for measurement error seems to create slight downward biases in the estimates of the returns to schooling only at the lower quantiles, if at all. But again, the IV estimates are less precise, particularly at the tails.

Does ability bias matter? Comparison of estimates from the levels models non-IV vs. father's educ models non-IV (Figure 5D) and levels models IV vs. father's educ models IV (Figure 5B) are revealing. First, the shapes of the curves are similar. There is an almost perfect overlap of the curves in the lower quantiles. Beyond the 0.40th quantile, the family models' curves are slightly above, so there is evidence of a slight upward ability bias in the right tail in models that do not account for endogeneity of schooling choices.

More important for the key question addressed in this paper is the fact that the pattern of return estimates is essentially unaffected by measurement error in both the levels models and all the family effects models. There is a tendency for returns to increase monotonically along the lower tail of the conditional wage distribution, returns then flatten out but tend to remain higher in the right tail. These findings are supported by our formal tests and suggest that differential endogeneity bias does not fully account for the patterns of heterogeneous increasing returns found in the base levels models. Some of this heterogeneity does seem to reflect actual differences in the market returns to schooling arising from a complementary relationship between education and ability which gives an advantage to those at the top of the conditional wage distribution but also enhances earnings potential for low-wage individuals.

\subsection{Estimation results for other Covariates}

\footnotetext{
${ }^{14}$ Remarkably the conclusions here actually hold for the other four covariate designs we use in the paper. These results also hold for the family effects models that are based on sibling's education.

${ }^{15}$ In fact the estimates from the sibling's education model do not reveal this "bump" at the right tail.
} 
We finally briefly describe the return to the other covariates included in our empirical model. Table 5 presents the returns to each of the variables for the "all" specification, which includes age, race, gender (see Amidon, 1997), married, union, and tenure, along with the associated 90\% confidence intervals for the levels models. ${ }^{16}$ Table 6 does the same for the family effects models. Figure 6 is a concise summary of the results. It presents results for the family effects model without IV. Note the anomalous negative effect of race on earnings which is also reported by Ashenfelter and Krueger (1994) and Ashenfelter and Rouse (1998), but that this cannot be estimated with precision at any quantile. The effect of marital status on earnings is positive but it is only significant at the median. The other three sets of results in the two tables are very similar to the findings depicted in Figure 6.

For most of the covariates, there is little heterogeneity in the returns, except for the female and union variables. Women in this sample earn about 18 percent less than men at low quantiles (0.1) but the gap widens to roughly 30 percent at higher quantiles (0.9). The returns to being covered by a union contract are also monotonically declining. At low quantiles $(0.1)$ the return to being unionized is roughly 0.3 and at upper quantiles the return is roughly zero. This last result is consistent with the recent work that explores the effect of unions on the structure and the change in the distribution of wages (DiNardo and Lemieux, 1996; DiNardo, Fortin and Lemieux, 1996).

\section{Concluding Comments}

In this paper we present estimates of a simple model of earnings and schooling choices in which we explore the relationship between education and ability in the generation of human capital without imposing a stringent parametric structure on this relationship. We use instrumental variables quantile regression and data on identical twins to isolate the causal link between education and earnings at different quantiles of the conditional distribution of wages, while dealing with potential biases that arise from the correlation between ability and schooling investment choices and the fact that observed education levels are imperfect measures of schooling.

The results suggest the existence of an important upward ability bias at the high quantiles in the estimates of the returns to education that do not account for the endogeneity of schooling choices. Nevertheless, the estimated returns to education accounting for the endogeneity of schooling are positive and significant consistent with the human capital model in which education enhances earnings potential. The results also suggest that the measurement error in schooling levels induces slight downward biases in the estimated returns to education in the low quantiles that are intensified by attempts to deal with the ability bias.

\footnotetext{
${ }^{16}$ The confidence intervals obtained from the bootstrap method for these quantiles are very similar and inference conclusions are essentially unchanged, except that as expected the latter tend to be narrower at the extreme
} 
More importantly, the results provide novel evidence of the existence of two sources of heterogeneity in the returns to education. First, there is some evidence of a differential heterogeneity effect by which more able individuals become more educated. The resulting endogeneity biases appear as apparent higher returns to education at the high quantiles. That is high-ability individuals appear to have higher returns to schooling. Therefore, the earlier estimates of heterogeneous returns to schooling from quantile wage regressions that do not control for unobserved ability (Buchinsky (1994) and Mwabu and Schultz (1996)) may be confounding this differential endogeneity bias with any actual within quantile difference in the marginal returns to education.

Second, once this endogeneity bias is accounted for, our results provide significant evidence that there is no unique causal effect of schooling and that for any particular individual the effect may be above or below the extensively documented OLS estimate depending on his or her unobservable abilities in the generation of earnings. In particular, the evidence supports the existence of a complementary relationship between ability and education which gives an advantage to those at the top of the conditional wage distribution but also enhances earnings potential for low-wage individuals. The results thus suggest that more able individuals may attain more schooling because of lower marginal costs and due to higher marginal benefits to each additional year of education.

These findings are at odds with the findings of Ashenfelter and Rouse (1998) of lower marginal returns for higher ability individuals after controlling for the endogeneity and measurement error in schooling, but are consistent with recent findings of Conneely and Uusitalo (1998) based on estimation of conditional mean wage functions. They are also consistent with Card's (1995a) proposition of a negative relationship between the marginal costs and the marginal returns to schooling along the distribution of abilities.

Our results thus reassure us that any formal structural model of schooling investments and earnings should allow for potential heterogeneity in the returns to education (Card, 1995a) and perhaps diverse changes over time at different points in the wage distribution (Buchinsky, 1994, Chay and Lee, 1996).

There are several ways in which our work can be extended. First, a readily available extension is a careful exploration of potential differential effects of observable individual characteristics such as union participation and gender in the returns to education across quantiles of wage residuals. We intend to do this in subsequent work. Second, it would be interesting to explore potential non-linearities in the relationship between schooling and log-earnings by allowing the returns to education to differ across different education levels as in Buchinsky (1994) and Mwabu and Schultz (1996). Third, one could try to explore the impact that the changes over time in quantile estimates of the returns to 
education have on the structure of wages and widening wage inequality while carefully addressing the endogeneity and measurement error biases which are likely to change over time. This last point faces data limitations and some challenging but interesting unsolved methodological problems, particularly exploring extensions of quantile regression methods to the analysis of panel data.

In a recent paper, Bound and Solon (1998) criticized the estimates of returns to education based on twins data questioning the assumption of independence between the earnings and optimal education choice disturbances. As they rightly argued, the validity of twins based estimates relies crucially on this assumption. In our final approach, the resulting estimated returns are never lower than 9 percent and can be as high as 13 percent at the top of the conditional distribution of wages. In the case of failure of this assumption, our estimates can be thought to provide rather tight bounds on the causal effect of education on earnings.

Finally, the existence of the two sources of heterogeneity suggests that typical estimates of the mean return to education based on OLS provide a rather incomplete characterization of the impact of education on labor market outcomes and are thus a poor guide for public policy. On the one hand, the differential endogeneity bias that arises because of ability-based differences in the marginal costs of education imply that there is room for policies aimed at promoting heavier schooling investment by individuals who face higher costs. On the other hand, the indication that apart from this differential ability bias, the returns to schooling are higher for those at the top of the conditional wage distribution suggests a limit on the extent to which schooling can compensate for differences in individual ability endowments. Even though a general educational policy will tend to increase the welfare of individuals in the society, its net impact on the long run distribution of incomes and wealth will depend on the initial distribution of abilities across the population. 


\section{References}

Amidon, Carole, 1997, "Are Female Wage Earners Experiencing Wage Discrimination: An Application of Quantile Regression," University of Illinois at Urbana-Champaign, June.

Angrist, Joshua, D., and Alan B. Krueger, 1991, "Does Compulsory Schooling Affect Schooling and Earnings?" Quarterly Journal of Economics, 196, November, pp. 979-1014.

Angrist, Joshua, D., and Alan B. Krueger, 1992 "Estimating the Payoff to Schooling Using the Vietnam-Era Draft Lottery,” National Bureau of Economic Research Working Paper: 4067, May.

Angrist, Joshua, D., and Whitney Newey, 1991, "Over-Identification Tests in Earnings Functions with Fixed Effects," Journal of Business and Economic Statistics, 9, July, pp. 317-23.

Ashenfelter, Orley, and Alan Krueger, 1994, "Estimates of the Returns to Schooling from a New Sample of Twins," American Economic Review, December, 84 (5), pp. 1157-1173.

Ashenfelter, Orley, and Cecilia Rouse, 1998, "Income, Schooling, and Ability: Evidence From a New Sample of Identical Twins," Quarterly Journal of Economics, 113(1), February, pp. 253-84.

Becker, Gary, 1967, Human Capital and the Personal Distribution of Income. Ann Arbor, University of Michigan Press.

Bound, John and G. Solon, 1998, "Double Trouble: On The Value of Twins-Based Estimation of the Return to Schooling,” National Bureau of Economic Research, Working Paper 6721.

Buchinsky, Moshe, 1994, "Changes in the U.S. Wage Structure 1963-1987: An Application of Quantile Regression,” Econometrica, March, 62 (2), pp. 405-58.

Buchinsky, Moshe, 1995, "Estimating the Asymptotic Covariance Matrix for Quantile Regression Models: A Montecarlo Study,” Journal of Econometrics, 68 , pp. 303-338.

Butcher, Kristin F., and Anne Case, 1994, "The Effect of Sibling Composition on Women's Education and Earnings," Quarterly Journal of Economics, 109, August, pp. 531-564.

Card, David, 1995a, "Earnings, Schooling and Ability Revisited," Research in Labor Economics, Solomon Polachek ed., JAI Press, Volume 14, pp. 23-48.

Card, David, 1995b, "Using Geographic Variation in College Proximity to Estimate the Return to Schooling," in L. Christofides, E. Grant, and R. Swidinsky, editors, Aspects of Labour Market Behaviour: Essays in Honor of John Vanderkamp, University of Toronto Press, pp. 201-22.

Chay, Kenneth, and David Lee, 1996, "Changes in Relative Wages in the 1980s: Returns to Observed and Unobserved Skills and Black-White Wage Differentials," Princeton University Industrial Relations Section Working Paper \#372.

Chen, L. A, 1988, "Regression Quantiles and Trimmed Least Squares Estimators for Structural Equations and Non-Linear Regression Models," Unpublished Ph.D. dissertation, University of Illinois at Urbana-Champaign. 
Conneely, K. and R. Uusitalo, 1998, "Estimating Heterogeneous Treatment Effects in the Becker Schooling Model," mimeo.

DiNardo, John, Nicole Fortin, and Thomas Lemieux, 1996, "Labor Market Institutions and the Distribution of Wages, 1973-1992: A Semiparametric Approach," Econometrica, 64 (5), pp. 10011044..

DiNardo, John, and Thomas Lemieux, 1996, "Diverging Male Wage Inequality in the United States and Canada, 1981-1988: Do Institutions Explain the Difference?," Industrial and Labor Relations Review, 50(4), July 1997, pp. 629-51.

Fitzenberger, Bernd, and C. Kurz, 1998, "New Insights on Earnings Trends Across Skill groups and Industries in West Germany," working paper.

Griliches, Zvi, 1977, "Estimating the Returns to Schooling: Some Econometric Problems," Econometrica, January, 45, pp. 1-22.

Griliches, Zvi, 1979, "Sibling Models and Data in Economics: Beginnings of A Survey," Journal of Political Economy, 87, S37-64.

Gutenbrunner, C. Jureckova, J., Koenker, R. and Portnoy, 1993, "Tests of linear hypotheses based on regression rank scores," Journal of Nonparametric Statistics, 2, pp. 307-331.

Heckman, James, and Solomon Polachek, 1974, "Empirical Evidence on the Functional Form of the Earnings-Schooling Relationship," Journal of the American Statistical Association, 69(346), 350-4.

Kane, Thomas J., and Cecilia E. Rouse, 1995, "Market Returns to Two- and Four-Year Colleges," American Economic Review, June, 85 (3), pp. 600-14.

Koenker, Roger, 1994, "Confidence Intervals for Regression Quantiles," In: Mandl, P. and Huskova, M. eds, Asymptotic Statistics: Proceedings of the 5th Prague Symposium, Physica-Verlag, Heidleberg, 1994.

Koenker, Roger. and D’Orey, V., 1993, "Computing regression quantiles," Applied Statistics, 36, pp. 383-393 and 43, pp. 410-414.

Koenker, Roger, and Gilbert Bassett, 1978, "Regression Quantiles," Econometrica, January, 46 (1), pp. $1-26$.

Koenker, Roger and Gilbert Bassett, 1982, "Robust Tests for Heteroscedasticity based on regression quantiles," Econometrica, January, 50 (1), pp. 43-61.

Koenker, Roger and Portnoy, Stephen, 1997, "Quantile Regression," Office of Research Working Paper \#97-0100, College of Commerce and Business Administration, University of Illinois at UrbanaChampaign

Machado, Jose A. F., and Jose Mata, 1999, “Sources of increased Wage Inequality,” working paper.

Mincer, Jacob, 1974, "Schooling, Experience and Earnings". National Bureau of Economic Research, Columbia University Press. 
Mwabu, Germano, and T. Paul Schultz, 1996,"Education Returns Across Quantiles of the Wage Function: Alternative Explanations for Returns to Education by Race in South Africa," American Economic Review, 86 (2), May, pp. 335-9.

Park, Jin Heum, 1994, "Returns to Schooling: A Peculiar Deviation from Linearity," Princeton University Industrial Relations Section Working Paper \#335.

Psacharopoulos, George and Ng, Y. C., 1994, "Earnings and Education in Latin America," Education Economics, 2(2), 187-207.

Powell, James, 1983, "The Asymptotic Normality of Two-Stage Least Absolute Deviations Estimators," Econometrica, September, 51 (5) pp. 1569-1575.

Pritchett, Lant, 1997, "Where has all the Education Gone?", PRD Working Paper Series No. 1581, The World Bank.

Ribeiro, Eduardo, 1996, The Effect of Personal Income Taxes on Labor Supply in Brazil: An Application of Quantile Regression, Ph.D. Dissertation, University of Illinois at Urbana-Champaign.

Rosen, Sherwin, 1973, "Income Generating Functions and Capital Accumulation," Harvard Institute of Economic Research, Discussion Paper 306.

Rouse, Cecilia, 1997, "Further Estimates of the Economic Return to Schooling from a New Sample of Twins," Princeton University Industrial Relations Section Working Paper \#388, July.

Sosa-Escudero, Walter, 1997, "Revenue and the Welfare Effects of Infrastructure in the Telecommunications Industry. A Quantile Regression Exploration," mimeo, University of Illinois at Urbana-Champaign. 
Table 1. MEANS, STANDARD ERRORS, AND MEDIANS

\begin{tabular}{lcc}
\hline \hline & Means & Medians \\
\hline Education & 14.13 & 14 \\
Father's education & $(2.04)$ & 12 \\
age & 12.24 & \\
& $(3.15)$ & 36 \\
white & 37.75 & \\
& $(11.37)$ & 1 \\
female & 0.92 & 1 \\
& $(0.275)$ & \\
married & 0.58 & 1 \\
union & $(0.494)$ & 0 \\
tenure & 0.62 & 5 \\
& $(0.483)$ & \\
\hline Log wage & 0.21 & 2.508 \\
\end{tabular}

Source: Data are from Ashenfelter \& Krueger (1991), Ashenfelter and Rouse (1998) and Rouse (1997). Wage figures are in real 1995 dollars.

Notes: Standard errors are in parentheses. Sample size is 858. 
TABLE 2. Estimates of the Return to Schooling

\begin{tabular}{|c|c|c|c|c|c|c|c|c|c|}
\hline & \multicolumn{5}{|c|}{ Levels } & \multicolumn{4}{|c|}{ Differences } \\
\hline & (1) & (2) & (3) & (4) & (5) & (6) & (7) & $(8)$ & (9) \\
\hline & LS & LS & LS & $\mathrm{IV}^{(\mathrm{b})}$ & $\mathrm{IV}^{(\mathrm{b})}$ & LS & LS & $\mathrm{IV}^{(\mathrm{c})}$ & $A \& K^{\prime} V^{(d)}$ \\
\hline \multirow[t]{2}{*}{ education } & 0.108 & 0.120 & 0.114 & 0.111 & 0.123 & 0.088 & 0.095 & 0.119 & 0.167 \\
\hline & (0.009) & (0.008) & (0.009) & (0.009) & (0.009) & (0.018) & (0.017) & (0.029) & $(0.043)$ \\
\hline \multirow[t]{2}{*}{ age } & 0.099 & 0.087 & 0.089 & 0.099 & 0.087 & & & & \\
\hline & (0.009) & (0.019) & (0.010) & (0.009) & $(0.010)$ & & & & \\
\hline \multirow[t]{2}{*}{$(\text { age })^{2}$} & -0.001 & -0.001 & -0.001 & -0.001 & -0.001 & & & & \\
\hline & $(.0001)$ & $(.0001)$ & $(.0001)$ & $(.0001)$ & $(.0001)$ & & & & \\
\hline \multirow[t]{2}{*}{ female } & -0.335 & -0.266 & -0.266 & -0.334 & -0.265 & & & & \\
\hline & $(0.035)$ & $(0.035)$ & $(0.035)$ & $(0.035)$ & $(0.035)$ & & & & \\
\hline \multirow[t]{2}{*}{ white } & -0.079 & -0.096 & -0.108 & -0.078 & -0.095 & & & & \\
\hline & $(0.063)$ & $(0.060)$ & $(0.060)$ & $(0.063)$ & $(0.060)$ & & & & \\
\hline \multirow[t]{2}{*}{ married } & & 0.080 & 0.082 & & 0.084 & & 0.012 & 0.016 & \\
\hline & & (0.044) & (0.044) & & (0.044) & & (0.066) & (0.066) & \\
\hline \multirow[t]{2}{*}{ union } & & 0.099 & 0.103 & & 0.100 & & 0.074 & 0.076 & \\
\hline & & $(0.042)$ & $(0.042)$ & & $(0.042)$ & & $(0.052)$ & $(0.052)$ & \\
\hline \multirow[t]{2}{*}{ tenure } & & 0.020 & 0.020 & & 0.020 & & 0.019 & 0.019 & \\
\hline & & (0.002) & $(0.002)$ & & $(0.002)$ & & (0.003) & (0.003) & \\
\hline father's & & & 0.013 & & & & & & \\
\hline educ & & & (0.006) & & & & & & \\
\hline $\mathrm{N}$ & 858 & 858 & 858 & 858 & 858 & 429 & 429 & 429 & 149 \\
\hline $\mathrm{R}^{2}$ & 0.339 & 0.395 & 0.397 & & & 0.052 & 0.128 & & \\
\hline
\end{tabular}

Notes: (a) The difference in education is the difference between the first twin's report of twin one and the second twin's report of twin 2.

(b) The instrument used is the twin's report of his or her own education.

(c) The instrument used in these analyses is twin 1's report of twin 2's education minus twin 2's report of twin 1's education.

(d) From Ashenfelter and Krueger (1994). Our sample size differs from Ashenfelter \& Krueger (1994) as we use an extract from Rouse (1997) which includes three additional years of the Princeton Twins Data. Rouse (1997) carefully points out that although she finds " ... the return to schooling among identical twins is around 10-12 percent per year of school completed ... Ashenfelter and Krueger's estimates are insignificantly different ..." 
TABLE 3A. LEVELS MODEL: QUANTILE REGRESSION ESTIMATES, WITH AND WITHOUT INSTRUMENTAL VARIABLES

\begin{tabular}{ccccccc}
\hline \hline Quantile & \multicolumn{3}{c}{ Panel A: Levels Model } & \multicolumn{3}{c}{ Panel B: Levels Model } \\
& \multicolumn{2}{c}{ Without Instrumental Variables } & \multicolumn{2}{c}{ With Instrumental Variables } \\
\hline & lower & return & upper bound & lower & return & upper \\
& bound & estimate & & bound & estimate & bound \\
0.05 & 0.0494 & 0.0924 & 0.1186 & -0.0216 & 0.0945 & 0.2107 \\
0.10 & 0.0546 & 0.0904 & 0.1049 & 0.0454 & 0.0995 & 0.1537 \\
0.15 & 0.0628 & 0.0848 & 0.1078 & 0.0555 & 0.0935 & 0.1315 \\
0.20 & 0.0666 & 0.0811 & 0.1117 & 0.0634 & 0.0933 & 0.1232 \\
0.25 & 0.0826 & 0.0944 & 0.1078 & 0.0741 & 0.0977 & 0.1212 \\
0.30 & 0.0828 & 0.1034 & 0.1249 & 0.0995 & 0.1182 & 0.1370 \\
0.35 & 0.1097 & 0.1121 & 0.1287 & 0.1092 & 0.1264 & 0.1436 \\
0.40 & 0.0954 & 0.1185 & 0.1344 & 0.1082 & 0.1247 & 0.1412 \\
0.45 & 0.1011 & 0.1251 & 0.1415 & 0.1044 & 0.1222 & 0.1401 \\
0.50 & 0.1008 & 0.1306 & 0.1464 & 0.1102 & 0.1279 & 0.1456 \\
0.55 & 0.1152 & 0.1332 & 0.1458 & 0.1175 & 0.1351 & 0.1527 \\
0.60 & 0.1154 & 0.1314 & 0.1484 & 0.1188 & 0.1360 & 0.1533 \\
0.65 & 0.1184 & 0.1305 & 0.1449 & 0.1191 & 0.1364 & 0.1538 \\
0.70 & 0.1199 & 0.1255 & 0.1489 & 0.1142 & 0.1351 & 0.1560 \\
0.75 & 0.1128 & 0.1326 & 0.1533 & 0.1065 & 0.1315 & 0.1564 \\
0.80 & 0.1109 & 0.1270 & 0.1499 & 0.0904 & 0.1237 & 0.1569 \\
0.85 & 0.1119 & 0.1323 & 0.1572 & 0.0786 & 0.1205 & 0.1624 \\
0.90 & 0.1062 & 0.1398 & 0.1657 & 0.0733 & 0.1291 & 0.1849 \\
0.95 & 0.1080 & 0.1313 & 0.1766 & -0.0103 & 0.1410 & 0.2923 \\
\hline
\end{tabular}

Note: These are the estimates and 90\% confidence intervals which are contained in FIGURE 1E and FIGURE 2E, respectively. The other independent variables we control for are age, age ${ }^{2}$, race, gender, married, union, and tenure. See the appendix for details on the methods. Testing for equality of returns at various quantiles - testing for heterogeneity - is done in TABLE 3B. 
TABLE 3B. LEVELS MODEL: TESTS OF EQUALITY OF RETURNS TO SCHOOLING FOR QUANTILE REGRESSION ESTIMATES, WITH AND WITHOUT INSTRUMENTAL VARIABLES

\begin{tabular}{cccccc}
\hline \hline & & \multicolumn{2}{c}{$\begin{array}{c}\text { Panel A: Levels Model without } \\
\text { Instrumental Variables }\end{array}$} & \multicolumn{2}{c}{$\begin{array}{c}\text { Panel B: Levels Model with } \\
\text { Instrumental Variables }\end{array}$} \\
\hline \multirow{2}{*}{ quantiles } & & t-statistic & p-value & t-statistic & p-value \\
0.10 & 0.25 & 0.0786 & 0.7793 & 0.0131 & 0.9088 \\
0.10 & 0.40 & 3.2112 & 0.0731 & 2.2727 & 0.1317 \\
0.10 & 0.50 & 5.8218 & 0.0158 & 2.4524 & 0.1173 \\
0.10 & 0.60 & 5.8600 & 0.0155 & 4.0262 & 0.0448 \\
0.10 & 0.75 & 5.3746 & 0.0204 & 2.7266 & 0.0987 \\
0.10 & 0.90 & 4.7411 & 0.0294 & 1.5828 & 0.2084 \\
0.25 & 0.40 & 6.4846 & 0.0109 & 4.5685 & 0.0326 \\
0.25 & 0.50 & 10.5326 & 0.0012 & 4.7471 & 0.0293 \\
0.25 & 0.60 & 10.8578 & 0.0010 & 7.3187 & 0.0068 \\
0.25 & 0.75 & 8.1182 & 0.0044 & 4.3845 & 0.0363 \\
0.25 & 0.90 & 5.2841 & 0.0215 & 2.3446 & 0.1257 \\
0.40 & 0.50 & 2.7590 & 0.0967 & 0.1444 & 0.7040 \\
0.40 & 0.60 & 2.1231 & 0.1451 & 1.3208 & 0.2505 \\
0.40 & 0.75 & 1.4341 & 0.2310 & 0.3021 & 0.5826 \\
0.40 & 0.90 & 1.2874 & 0.2565 & 0.0593 & 0.8077 \\
0.50 & 0.60 & 0.0150 & 0.9024 & 1.1124 & 0.2916 \\
0.50 & 0.75 & 0.0394 & 0.8426 & 0.0988 & 0.7532 \\
0.50 & 0.90 & 0.2581 & 0.6114 & 0.0044 & 0.9473 \\
0.60 & 0.75 & 0.0213 & 0.8840 & 0.2581 & 0.6115 \\
0.60 & 0.90 & 0.2319 & 0.6301 & 0.1742 & 0.6764 \\
0.75 & 0.90 & 0.1980 & 0.6564 & 0.0241 & 0.8766 \\
\hline
\end{tabular}

Note: This table corresponds to Table 3A which presents estimated returns to schooling for the levels model with and without instrumental variables. These tests (and TABLE 3A) correspond to FIGURES 1E and 2E. The other independent variables we control for are age, age ${ }^{2}$, race, gender, married, union, and tenure. Standard errors are based on the bootstrap and the percentile method. See the appendix for details on the methods. 
TABLE 4A. FAMILY EFFECTS MODEL: QUANTILE REGRESSION ESTIMATES, WITH AND WITHOUT INSTRUMENTAL VARIABLES

\begin{tabular}{ccccccc}
\hline \hline Quantile & \multicolumn{2}{c}{ Panel A: Family Effect Model } & \multicolumn{3}{c}{ Panel B: Family Effect Model } \\
& \multicolumn{2}{c}{ Without Instrumental Variables } & \multicolumn{2}{c}{ With Instrumental Variables } \\
\hline & lower & return & upper bound & lower & return & upper \\
& bound & estimate & & bound & estimate & bound \\
0.05 & 0.0467 & 0.0876 & 0.1223 & -0.0257 & 0.0987 & 0.2230 \\
0.10 & 0.0544 & 0.0918 & 0.1022 & 0.0450 & 0.1013 & 0.1575 \\
0.15 & 0.0611 & 0.0872 & 0.1075 & 0.0615 & 0.0975 & 0.1336 \\
0.20 & 0.0665 & 0.0809 & 0.1073 & 0.0559 & 0.0905 & 0.1252 \\
0.25 & 0.0771 & 0.0903 & 0.1084 & 0.0724 & 0.0981 & 0.1237 \\
0.30 & 0.0821 & 0.1009 & 0.1230 & 0.0966 & 0.1171 & 0.1375 \\
0.35 & 0.0967 & 0.1123 & 0.1276 & 0.1069 & 0.1266 & 0.1463 \\
0.40 & 0.0957 & 0.1148 & 0.1311 & 0.1046 & 0.1237 & 0.1429 \\
0.45 & 0.1029 & 0.1212 & 0.1382 & 0.1005 & 0.1195 & 0.1384 \\
0.50 & 0.1081 & 0.1222 & 0.1449 & 0.1040 & 0.1226 & 0.1412 \\
0.55 & 0.1105 & 0.1290 & 0.1381 & 0.1043 & 0.1226 & 0.1409 \\
0.60 & 0.1121 & 0.1269 & 0.1456 & 0.1044 & 0.1226 & 0.1407 \\
0.65 & 0.1163 & 0.1293 & 0.1415 & 0.1082 & 0.1264 & 0.1446 \\
0.70 & 0.1154 & 0.1282 & 0.1422 & 0.1068 & 0.1288 & 0.1509 \\
0.75 & 0.1077 & 0.1274 & 0.1422 & 0.1007 & 0.1310 & 0.1614 \\
0.80 & 0.1062 & 0.1203 & 0.1417 & 0.0771 & 0.1137 & 0.1503 \\
0.85 & 0.1078 & 0.1233 & 0.1362 & 0.0609 & 0.1051 & 0.1494 \\
0.90 & 0.1059 & 0.1264 & 0.1501 & 0.0455 & 0.1070 & 0.1684 \\
0.95 & 0.0955 & 0.1263 & 0.1454 & -0.0220 & 0.1316 & 0.2851 \\
\hline
\end{tabular}

Note: These are the estimates and 90\% confidence intervals which are contained in FIGURE 3E and FIGURE 4E, respectively. The other independent variables we control for are age, age ${ }^{2}$, race, gender, married, union, and tenure. Testing for equality of returns at various quantiles testing for heterogeneity - is done in TABLE 4B. 
TABLE 4B. FAMILY EFFECTS MODELS: TESTS OF EQUALITY OF RETURNS TO SCHOOLING FOR QUANTILE REGRESSION ESTIMATES, WITH AND WITHOUT INSTRUMENTAL VARIABLES

\begin{tabular}{|c|c|c|c|c|c|}
\hline & & \multicolumn{2}{|c|}{$\begin{array}{l}\text { Panel A: Family Model without } \\
\text { Instrumental Variables }\end{array}$} & \multicolumn{2}{|c|}{$\begin{array}{l}\text { Panel B: Family Model with } \\
\text { Instrumental Variables }\end{array}$} \\
\hline \multicolumn{2}{|c|}{ quantiles } & t-statistic & p-value & t-statistic & p-value \\
\hline 0.10 & 0.25 & 0.0125 & 0.9109 & 0.0477 & 0.8272 \\
\hline 0.10 & 0.40 & 2.2160 & 0.1366 & 1.8157 & 0.1778 \\
\hline 0.10 & 0.50 & 3.5899 & 0.0581 & 1.5928 & 0.2069 \\
\hline 0.10 & 0.60 & 4.4499 & 0.0349 & 1.4776 & 0.2242 \\
\hline 0.10 & 0.75 & 4.1529 & 0.0416 & 2.3301 & 0.1269 \\
\hline 0.10 & 0.90 & 2.4927 & 0.1144 & 0.0640 & 0.8003 \\
\hline 0.25 & 0.40 & 7.1765 & 0.0074 & 3.9971 & 0.0456 \\
\hline 0.25 & 0.50 & 8.4828 & 0.0036 & 2.9040 & 0.0884 \\
\hline 0.25 & 0.60 & 9.2836 & 0.0023 & 2.5983 & 0.1070 \\
\hline 0.25 & 0.75 & 7.4266 & 0.0064 & 3.5512 & 0.0595 \\
\hline 0.25 & 0.90 & 3.6078 & 0.0575 & 0.1807 & 0.6708 \\
\hline 0.40 & 0.50 & 1.1163 & 0.2907 & 0.0152 & 0.9019 \\
\hline 0.40 & 0.60 & 1.8903 & 0.1692 & 0.0098 & 0.9210 \\
\hline 0.40 & 0.75 & 1.2116 & 0.2710 & 0.2918 & 0.5891 \\
\hline 0.40 & 0.90 & 0.4400 & 0.5071 & 0.8283 & 0.3628 \\
\hline 0.50 & 0.60 & 0.4301 & 0.5119 & 0.0000 & 0.9983 \\
\hline 0.50 & 0.75 & 0.2408 & 0.6237 & 0.4922 & 0.4829 \\
\hline 0.50 & 0.90 & 0.0645 & 0.7995 & 0.7518 & 0.3859 \\
\hline 0.60 & 0.75 & 0.0030 & 0.9565 & 0.6366 & 0.4249 \\
\hline 0.60 & 0.90 & 0.0010 & 0.9743 & 0.8467 & 0.3575 \\
\hline 0.75 & 0.90 & 0.0049 & 0.9443 & 2.4279 & 0.1192 \\
\hline
\end{tabular}

Note: This table corresponds to Table 4A which presents estimated returns to schooling for the levels model with and without instrumental variables. These tests (and TABLE 4A) correspond to FIGURES 3E and 4E. The other independent variables we control for are age, age $^{2}$, race, gender, married, union, and tenure. Standard errors are based on the bootstrap and the percentile method. See the appendix for details on the methods. 
TABLE 5. LEVELS MODELS: QUANTILE REGRESSION ESTIMATES FOR ALL VARIABLES

$\begin{array}{lccccc}\text { PANEL A: LEVEL MODEL WITHOUT INSTRUMENTS } & & \\ & 0.10 & 0.25 & 0.50 & 0.75 & 0.90 \\ \text { education } & 0.090 & & & & \\ & (0.055,0.105) & (0.083,0.109) & (0.115,0.146) & (0.113,0.153) & (0.106,0.166) \\ \text { age } & 0.081 & 0.094 & 0.091 & 0.088 & 0.063 \\ & (0.058,0.106) & (0.071,0.106) & (0.074,0.106) & (0.060,0.124) & (0.027,0.118) \\ \text { (age })^{2} & -0.001 & -0.001 & -0.001 & -0.001 & -0.001 \\ & (-0.001,-0.001) & (-0.001,-0.001) & (-0.001,-0.001) & (-0.001,-0.001) & (-0.001,-0.000) \\ \text { female } & -0.182 & -0.204 & -0.212 & -0.277 & -0.351 \\ & (-0.248,-0.065) & (-0.266,-0.135) & (-0.269,-0.167) & (-0.344,-0.201) & (-0.521,-0.197) \\ \text { white } & -0.066 & -0.136 & -0.106 & -0.097 & -0.150 \\ & (-0.263,0.060) & (-0.208,0.020) & (-0.205,-0.004) & (-0.302,0.032) & (-0.336,0.056) \\ \text { union } & 0.296 & 0.164 & 0.056 & 0.082 & -0.020 \\ & (0.197,0.368) & (0.094,0.231) & (0.005,0.138) & (-0.024,0.136) & (-0.145,0.087) \\ \text { married } & 0.116 & 0.036 & 0.067 & 0.075 & 0.112 \\ & (-0.058,0.214) & (-0.016,0.150) & (-0.003,0.143) & (-0.027,0.161) & (-0.090,0.187) \\ \text { tenure } & 0.017 & 0.023 & 0.021 & 0.019 & 0.021 \\ & (0.014,0.021) & (0.020,0.027) & (0.017,0.025) & (0.013,0.026) & (0.013,0.032) \\ \text { intercept } & -0.996 & -0.900 & -1.166 & -0.848 & -0.081 \\ & (-1.540,-0.196) & (-1.293,-0.405) & (-1.507,-0.923) & (-1.412,-0.400) & (-1.079,0.909)\end{array}$

PANEL B: LEVELS MODEL WITH INSTRUMENTS

$\begin{array}{lccccc} & 0.10 & 0.25 & 0.50 & 0.75 & 0.90 \\ \text { education } & 0.100 & 0.098 & 0.128 & 0.132 & 0.129 \\ & (0.045,0.154) & (0.074,0.121) & (0.110,0.146) & (0.107,0.156) & (0.073,0.185) \\ \text { age } & 0.093 & 0.085 & 0.092 & 0.096 & 0.066 \\ & (0.036,0.150) & (0.061,0.110) & (0.073,0.110) & (0.070,0.123) & (0.007,0.125) \\ \text { (age })^{2} & -0.001 & -0.001 & -0.001 & -0.001 & -0.001 \\ & (-0.002,-0.000) & (-0.001,-0.001) & (-0.001,-0.001) & (-0.001,-0.001) & (-0.001,0.000) \\ \text { female } & -0.153 & -0.206 & -0.224 & -0.263 & -0.354 \\ \text { white } & (-0.359,0.054) & (-0.296,-0.116) & (-0.291,-0.156) & (-0.358,-0.168) & (-0.567,-0.142) \\ & -0.116 & -0.130 & -0.123 & -0.112 & -0.131 \\ \text { union } & (-0.468,0.237) & (-0.284,0.023) & (-0.239,0.008) & (-0.275,0.050) & (-0.495,0.233) \\ & 0.272 & 0.172 & 0.065 & 0.014 & -0.002 \\ \text { married } & (0.023,0.521) & (0.063,0.281) & (-0.017,0.146) & (-0.101,0.129) & (-0.259,0.255) \\ \text { tenure } & 0.056 & 0.075 & 0.098 & 0.067 & 0.088 \\ & (-0.205,0.316) & (-0.039,0.188) & (0.013,0.183) & (-0.054,0.187) & (-0.180,0.357) \\ \text { intercept } & 0.018 & 0.024 & 0.021 & 0.018 & 0.019 \\ & (0.004,0.033) & (0.018,0.030) & (0.016,0.025) & (0.011,0.024) & (0.004,0.034) \\ & -1.318 & -0.813 & -1.116 & -0.981 & 0.045 \\ & (-2.646,0.011) & (-1.391,-0.234) & (-1.550,-0.681) & (-1.594,-0.369) & (-1.324,1.413)\end{array}$


TABLE 6. "FAMILY EFFECTS" MODELS: QUANTILE REGRESSION ESTIMATES FOR ALL VARIABLES

$\begin{array}{lccccc}\text { PANEL A: "FAMILY EFFECTS" MODEL WITHOUT INSTRUMENTS } & \\ \text { education } & 0.10 & 0.25 & 0.50 & 0.75 & 0.90 \\ & 0.092 & 0.090 & 0.122 & 0.127 & 0.126 \\ \text { father's } & (0.054,0.102) & (0.077,0.108) & (0.108,0.145) & (0.108,0.142) & (0.106,0.150) \\ \text { education } & 0.004 & 0.004 & 0.009 & 0.017 & 0.033 \\ \text { age } & (-0.008,0.016) & (-0.007,0.017) & (-0.002,0.018) & (0.007,0.023) & (0.014,0.047) \\ & 0.083 & 0.096 & 0.096 & 0.087 & 0.071 \\ \text { (age) })^{2} & (0.057,0.107) & (0.071,0.112) & (0.076,0.111) & (0.067,0.108) & (0.035,0.108) \\ & -0.001 & -0.001 & -0.001 & -0.001 & -0.001 \\ \text { female } & (-0.001,-0.001) & (-0.001,-0.001) & (-0.001,-0.001) & (-0.001,-0.001) & (-0.001,-0.000) \\ & -0.178 & -0.207 & -0.227 & -0.266 & -0.313 \\ \text { white } & (-0.248,-0.087) & (-0.266,-0.140) & (-0.278,-0.157) & (-0.337,-0.212) & (-0.454,-0.195) \\ & -0.083 & -0.136 & -0.124 & -0.090 & -0.206 \\ \text { union } & (-0.265,0.071) & (-0.215,0.017) & (-0.203,-0.029) & (-0.307,0.023) & (-0.382,0.010) \\ & 0.298 & 0.169 & 0.058 & 0.058 & 0.027 \\ \text { married } & (0.204,0.367) & (0.088,0.229) & (-0.026,0.144) & (-0.001,0.135) & (-0.105,0.175) \\ & 0.117 & 0.041 & 0.060 & 0.080 & 0.100 \\ \text { tenure } & (-0.046,0.213) & (-0.033,0.150) & (0.009,0.128) & (-0.033,0.152) & (-0.101,0.205) \\ & 0.016 & 0.023 & 0.020 & 0.019 & 0.021 \\ \text { intercept } & (0.014,0.021) & (0.019,0.027) & (0.014,0.024) & (0.012,0.027) & (0.012,0.030) \\ & -1.072 & -0.925 & -1.227 & -0.969 & -0.419 \\ & (-1.655,-0.093) & (-1.349,-0.424) & (-1.519,-0.888) & (-1.332,-0.668) & (-1.288,0.571)\end{array}$

PANEL B: "FAMILY EFFECTS" MODEL WITH INSTRUMENTS

$\begin{array}{lccccc} & 0.10 & 0.25 & 0.50 & 0.75 & 0.90 \\ \text { education } & 0.101 & 0.098 & 0.123 & 0.131 & 0.107 \\ & (0.045,0.158) & (0.072,0.124) & (0.104,0.141) & (0.101,0.161) & (0.046,0.168) \\ \text { father's } & -0.003 & -0.001 & 0.011 & 0.010 & 0.041 \\ \text { education } & (-0.043,0.038) & (-0.019,0.018) & (-0.003,0.024) & (-0.012,0.032) & (-0.003,0.085) \\ \text { age } & 0.092 & 0.086 & 0.095 & 0.095 & 0.064 \\ & (0.037,0.147) & (0.061,0.111) & (0.076,0.113) & (0.065,0.125) & (0.004,0.124) \\ \text { (age })^{2} & -0.001 & -0.001 & -0.001 & -0.001 & -0.001 \\ & (-0.002,-0.000) & (-0.001,-0.001) & (-0.001,-0.001) & (-0.001,-0.001) & (-0.001,0.000) \\ \text { female } & -0.156 & -0.204 & -0.220 & -0.262 & -0.319 \\ & (-0.354,0.042) & (-0.295,-0.114) & (-0.286,-0.155) & (-0.369,-0.155) & (-0.535,-0.103) \\ \text { white } & -0.102 & -0.131 & -0.134 & -0.123 & -0.104 \\ & (-0.443,0.239) & (-0.286,0.024) & (-0.247,-0.021) & (-0.307,0.061) & (-0.476,0.268) \\ \text { union } & 0.275 & 0.170 & 0.086 & 0.013 & 0.059 \\ & (0.036,0.515) & (0.061,0.279) & (0.007,0.166) & (-0.116,0.143) & (-0.202,0.321) \\ \text { married } & 0.056 & 0.072 & 0.087 & 0.063 & 0.040 \\ & (-0.195,0.306) & (-0.042,0.186) & (0.004,0.170) & (-0.072,0.198) & (-0.233,0.312) \\ \text { tenure } & 0.018 & 0.024 & 0.019 & 0.018 & 0.020 \\ & (0.004,0.032) & (0.018,0.031) & (0.015,0.024) & (0.010,0.026) & (0.004,0.035) \\ \text { intercept } & -1.289 & -0.814 & -1.237 & -1.077 & -0.218 \\ & (-2.602,0.023) & (-1.412,-0.216) & (-1.671,-0.802) & (-1.786,-0.368) & (-1.650,1.215)\end{array}$


Figure 1. Returns to Schooling: Levels, No IV

Note: Estimation Performed in S+: see text
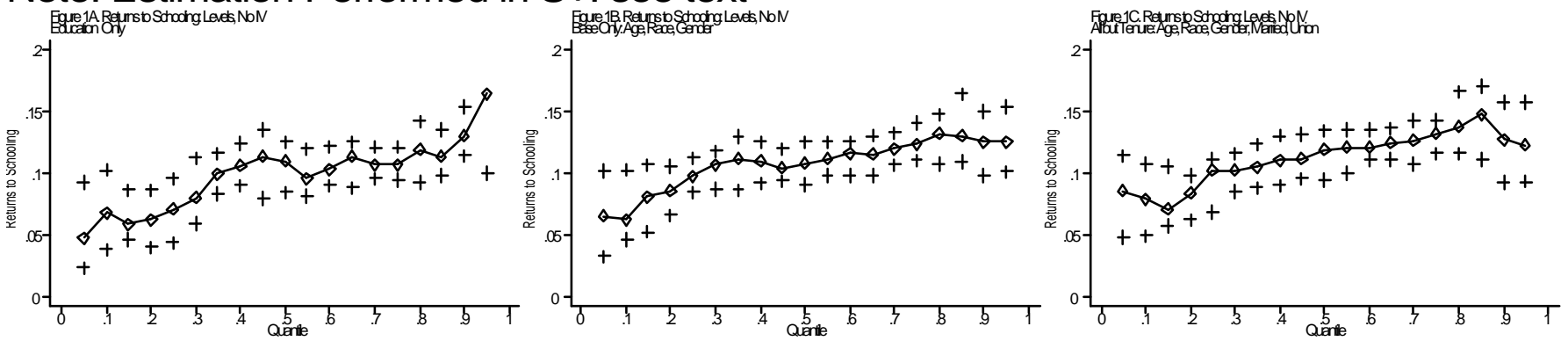

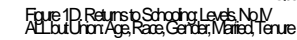

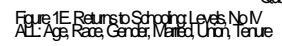
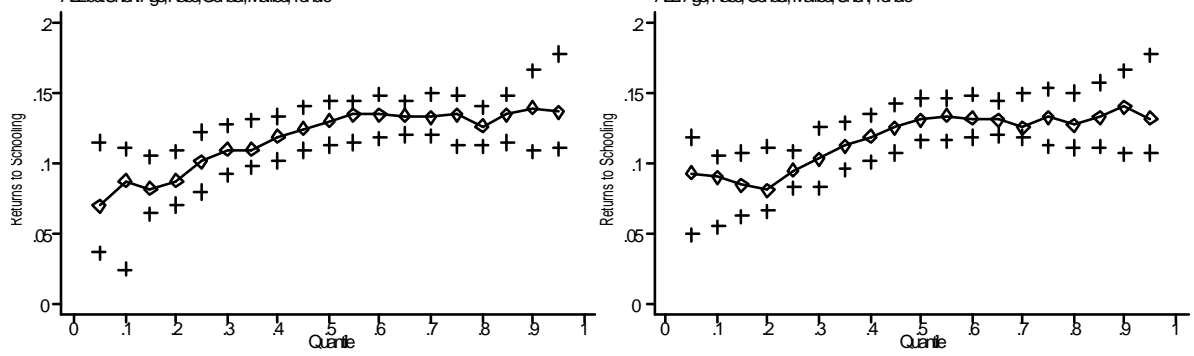
Figure 2. Returns to Schooling: Levels, IV

Note: Estimation Performed in S+: See Text
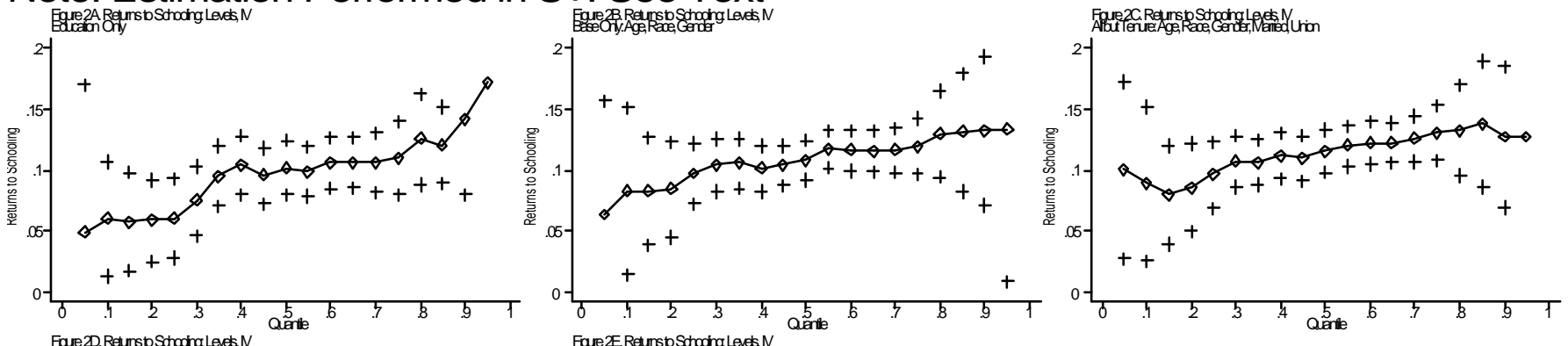

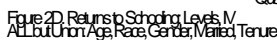
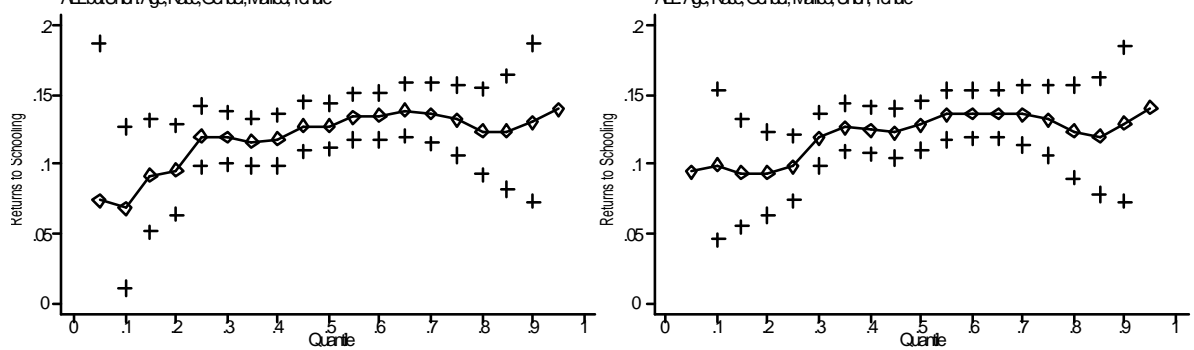
Figure 3. Returns to Schooling: Family Effect, No IV

Note: Estimation Performed in $\mathrm{S}+$ : see text
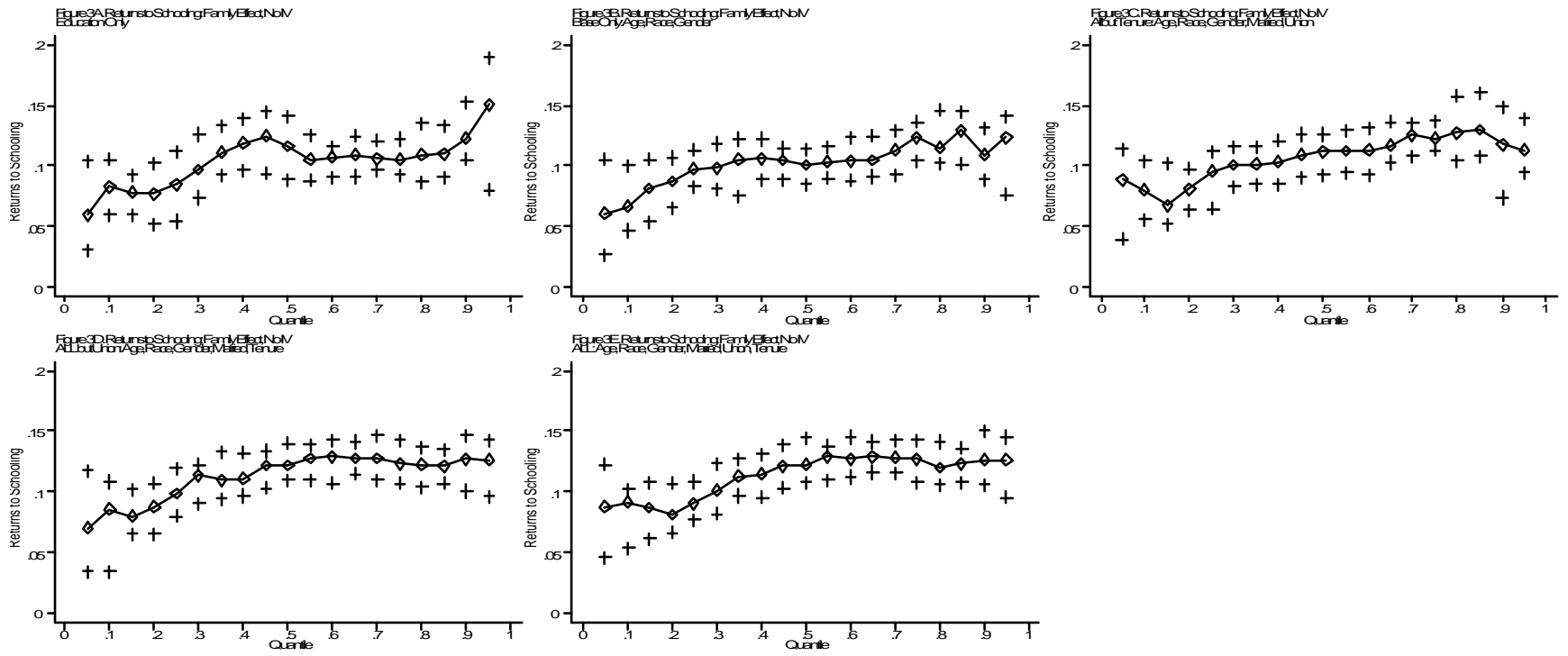
Figure 4. Returns to Schooling: Family Effect, IV

Note: Estimation Performed in $\mathrm{S}_{+}$, see text
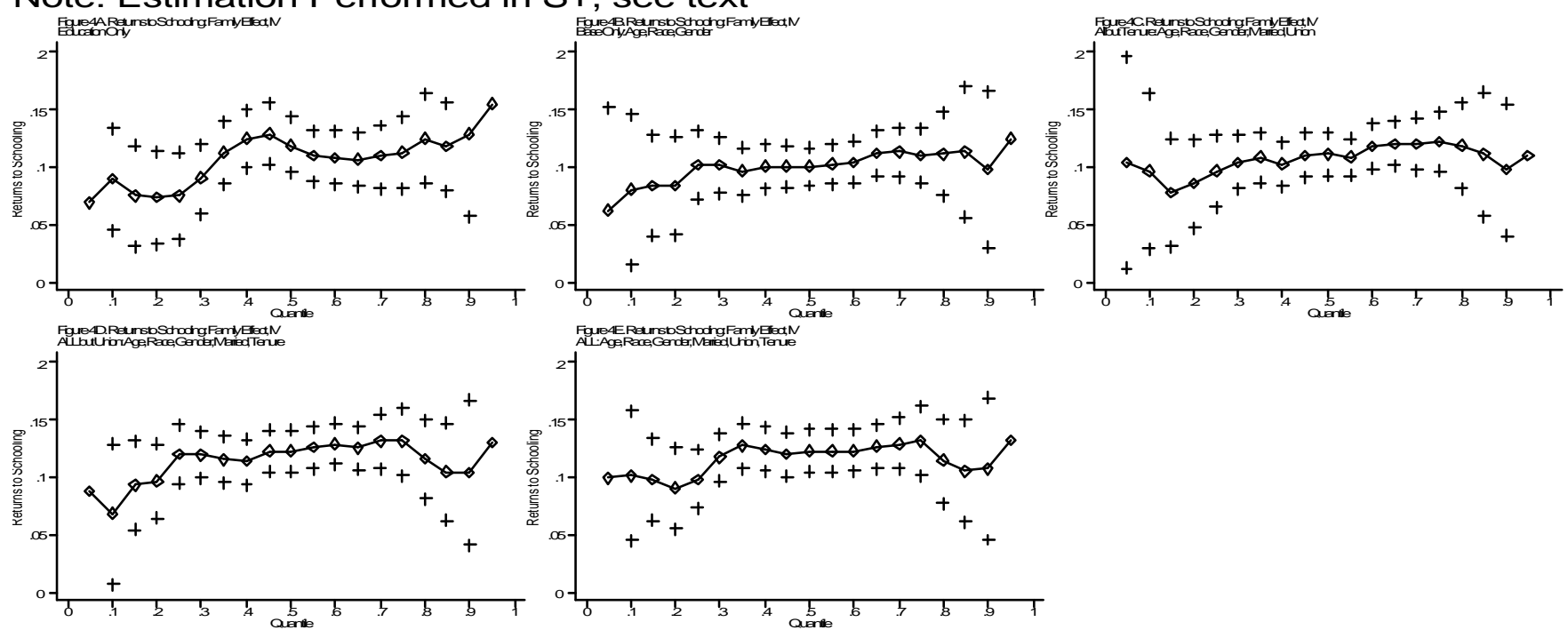
Figure 5. Differences in Returns to Schooling by Empirical Model

Note: Estimation Performed in S+: see text

Figure 5A. Levels non-IV (Figure 1E) - Levels IV (Figure 2E)

Figure 5B. Levels IV (Figure 2E) - Family IV (Figure 4E)
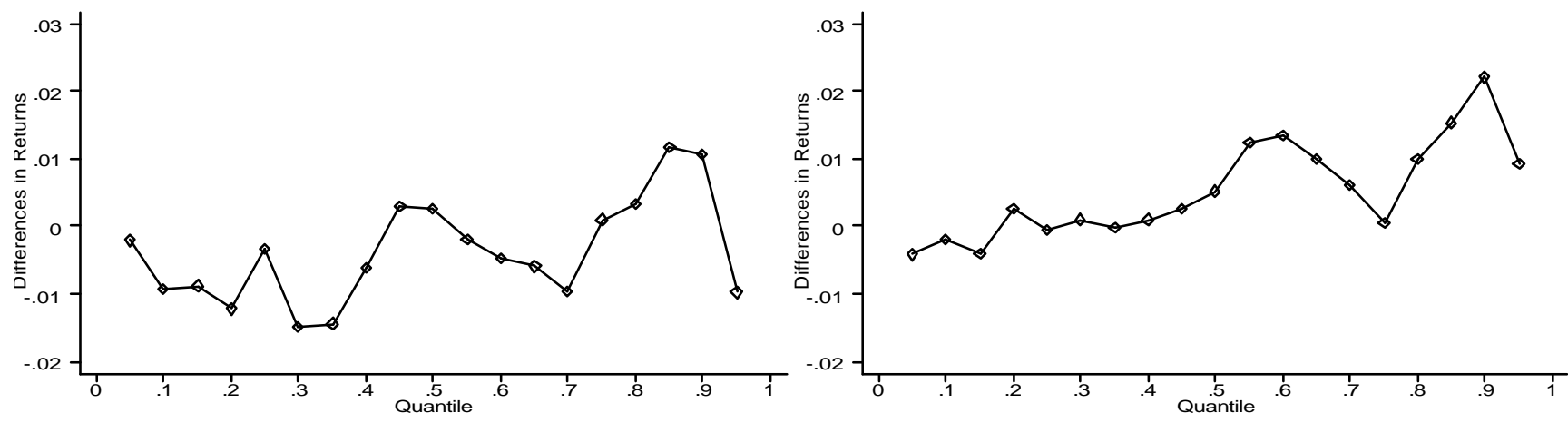

Figure 5C. Family non-IV (Figure 3E) - Family IV (Figure 4E)
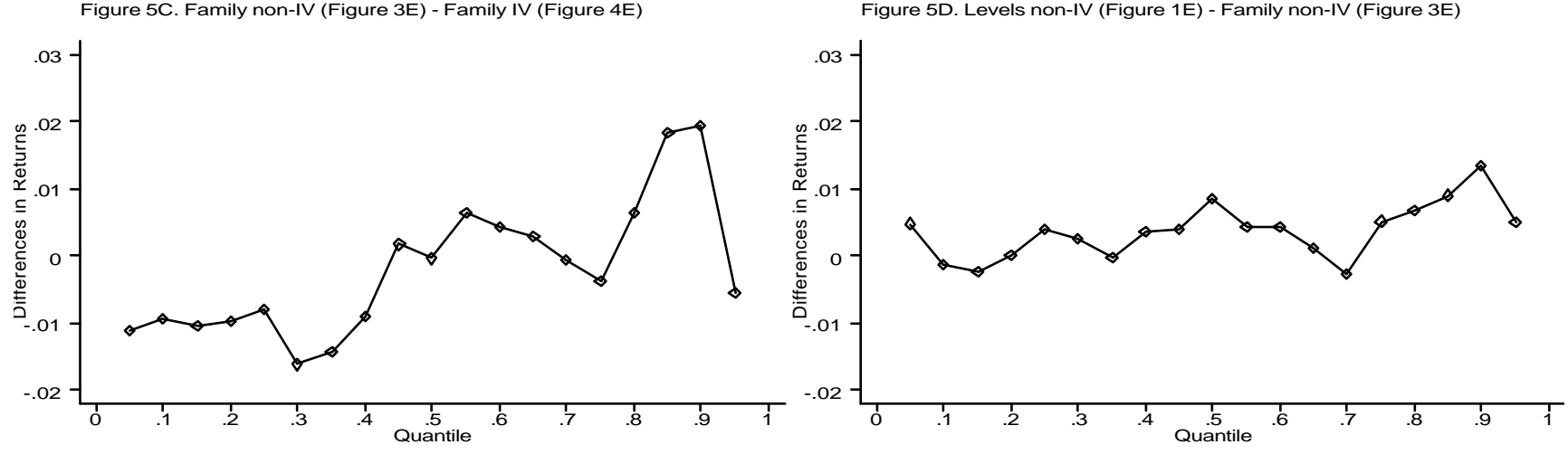
Figure 6. Returns to Other Covariates: Family Effects Model, No IV Note: Estimation Performed in $\mathrm{S}_{+}$, see text
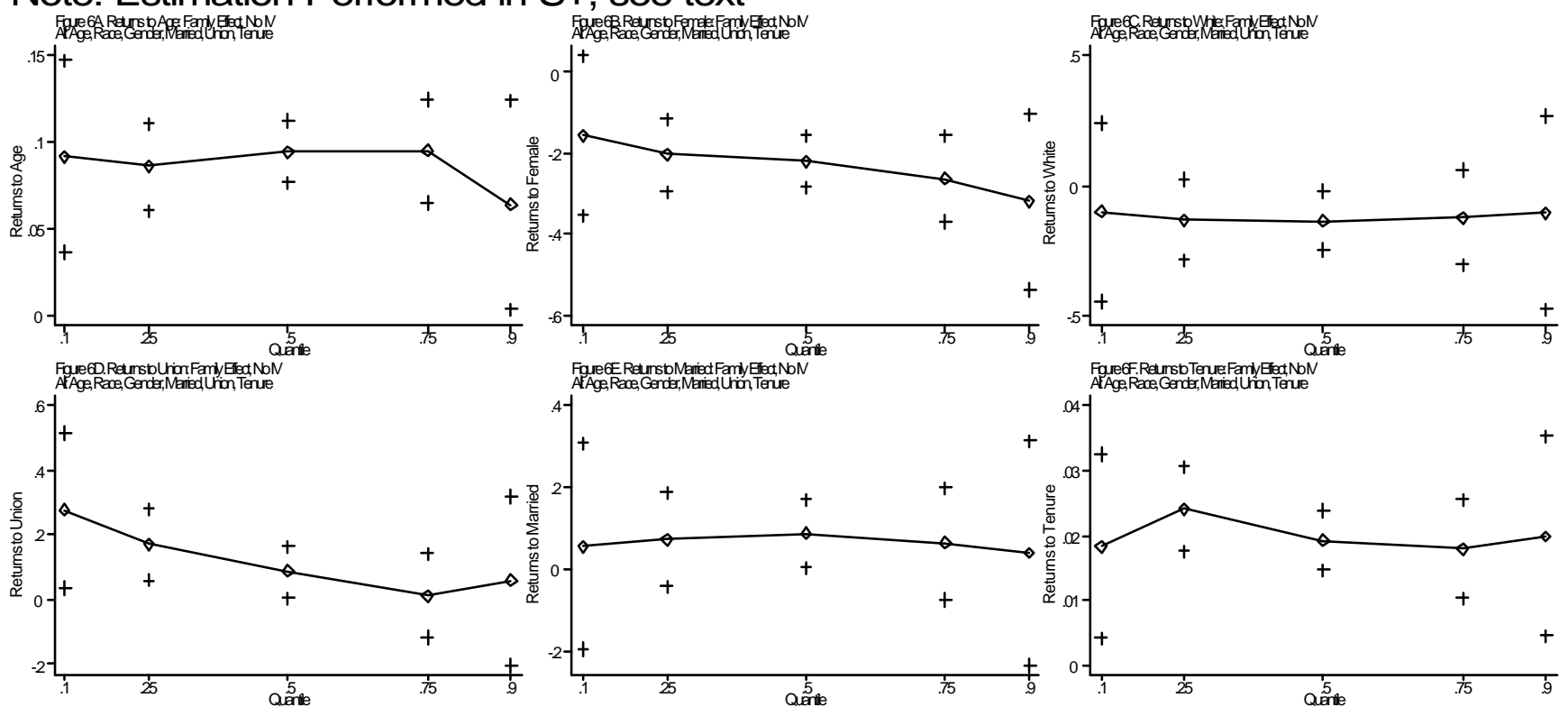
Appendix Figure. Returns to Family Effects Note: Estimation Performed in $\mathrm{S}_{+}$, see text

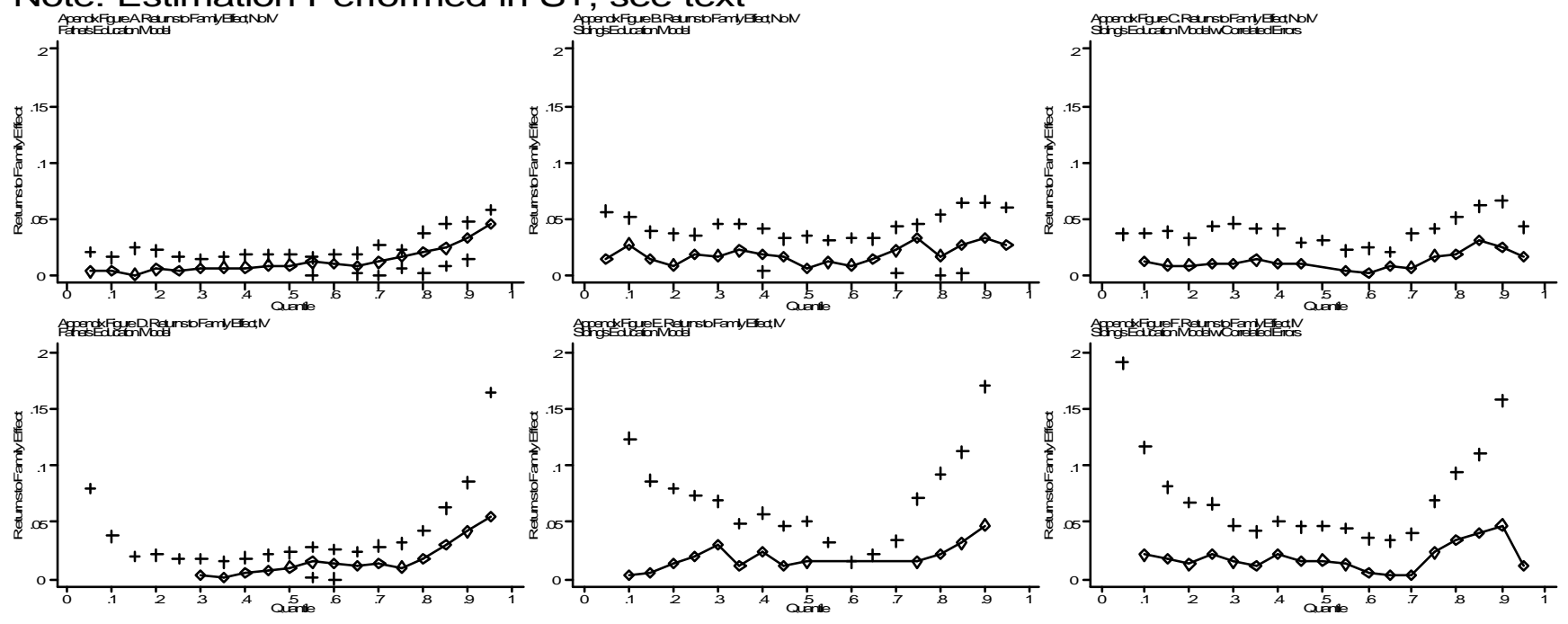




\section{Appendix: Details on Quantile Regression Used in This Work}

\section{Regression Quantiles}

In this section we present some basic results on the quantile regression methods used in this work. This exposition is largely based on Sosa-Escudero (1997). See Koenker and Portnoy (1997) for a recent comprehensive overview of the topic. The problem of estimating a relationship between a random variable $Y$ and a set of explanatory variables $X$ is traditionally reduced in econometric practice to formulating a model for the mean of $Y$ conditional on $X$, and a particular functional form is specified for this (mean) regression equation. In particular, it is typical to consider the following linear model:

$$
Y=X \beta+u
$$

where $u$ is a vector of independent error terms whose $i$-th component has an unspecified distribution function $F_{i}$. Given the usual conditional orthogonality assumption on the error term, Ordinary Least Squares regression provides a model for the conditional mean of $\mathrm{Y}$ given by:

$$
E[Y / X]=X \hat{\beta}
$$

In the special case of iid errors this Least Squares estimate of the conditional mean function together with some measure of dispersion would usually provide a complete characterization of (10). If additionally, $F_{i}$ is assumed to be Gaussian, then OLS regression yields the optimal estimator of location for the linear model (10).

Nevertheless, econometricians are increasingly recognizing that the iid linear model is not well suited to analyze some real world problems which very often involve heterogeneous populations. In this case if the purpose of the modeling problem is to provide a complete characterization of the conditional distribution of $Y$ on $X$ one needs to think of summary measures other than the mean. In general, one could formulate the following model for the $\tau$-th conditional quantile of $Y$ :

$$
Q_{\tau}=\mathrm{X} \beta(\tau)
$$

where the orthogonality condition on $u$ is now assumed for $\mathrm{Q}_{\tau}(u \mid \mathrm{X})$, that is, the $\tau$-th conditional quantile of the error term is assumed to be zero. This gives rise to a family of (quantile) regression curves, one for each $\tau$, which provide a more complete characterization of the relationship between $Y$ and $X$ compared to the one given by the mean regression, which concentrates on the first conditional moment. Estimation of the $\beta(\tau)$ coefficients (called "regression quantiles") is based on a sample of $n$ observations of $Y$ and $p$ explanatory variables collected in the matrix $X$. It can be shown that estimates of $\beta(\tau)$ can be obtained as solutions to the following linear programming problem (see Koenker and D’Orey (1993) ): 


$$
\min _{(\beta, \mathrm{u}, \mathrm{v}) \in R^{p} x R_{+}^{2 n}}\left[\tau 1^{\prime}{ }_{\mathrm{n}} u+(1-\tau) 1_{\mathrm{n}}^{\prime} v \mid X \beta+u-v=Y\right]
$$

where $1^{\prime}{ }_{n}$ is an $n$ vector of ones and $u$ and $v$ are the positive and negative parts of the residual vector. In addition to providing a more complete representation of the relationship of interest, quantile regression offers the usual robustness properties associated with ordinary sample quantiles since the quantile regression estimator is robust to outlying observations in $Y$. Note that in the case of the iid linear model the conditional quantile functions given in (12) will be parallel vertical displacements of one another. In this case only robustness arguments would lead one to prefer alternative estimators of location other than OLS.

An interesting case arises when the estimated $\beta(\tau)$ coefficients differ systematically across $\tau$ 's, suggesting that the marginal effect of a particular explanatory variable is not homogeneous across different quantiles of the conditional distribution of Y. This quantile regression model introduced by Koenker and Bassett (1978) provides a semiparametric alternative to least squares that handles heterogeneously distributed unobservables in an informative and constructive fashion

Inference on the $\beta(\tau)$ 's can be based on the following result. Let $b_{n}=\left(b_{n}\left(\tau_{1}\right), \ldots b_{n}\left(\tau_{m}\right)\right)$ be a $p m$ vector of $p$ estimated regression quantile coefficients for $m$ different quantiles based on a sample of $n$ iid observations; and let $\beta$ be its population counterpart. Under some regularity conditions Koenker and Basset (1978) showed that:

$$
\sqrt{\mathrm{n}}\left(\mathrm{b}_{\mathrm{n}}-\beta\right) \rightarrow N\left(0, \Omega \otimes \mathrm{Q}_{0}{ }^{-1}\right)
$$

where $\Omega$ is a $m \times m$ matrix with typical element:

$$
\omega_{i j}=\left(\min \left(\tau_{\mathrm{i}}, \tau_{\mathrm{j}}\right)-\tau_{\mathrm{i}} \tau_{\mathrm{j}}\right) /\left[\mathrm{f}\left(\mathrm{F}^{-1}\left(\tau_{\mathrm{i}}\right)\right) \mathrm{f}\left(\mathrm{F}^{-1}\left(\tau_{\mathrm{j}}\right)\right)\right]
$$

$\mathrm{Q}_{0}=$ plim $\mathrm{n}^{-1}\left(X^{\prime} X\right)$, a positive definite matrix, and $\otimes$ denotes the Kronecker product. Confidence intervals can be easily constructed based on this result. General linear hypothesis like $\mathrm{H}_{0}: H \beta=h$ can be tested using the following Wald-type statistic:

$$
\mathrm{T}_{\mathrm{n}}=\left(\mathrm{H} \mathrm{b}_{\mathrm{n}}-\mathrm{h}\right)^{\prime}\left[\mathrm{H}\left(\Omega \otimes\left(\mathrm{X}^{\prime} \mathrm{X}\right)^{-1}\right) \mathrm{H}^{\prime}\right]^{-1}\left(\mathrm{H} \mathrm{b} \mathrm{b}_{\mathrm{n}}-\mathrm{h}\right)
$$

which under the null hypothesis has a $\chi^{2}$ distribution with $\operatorname{rank}(H)$ degrees of freedom. This approach requires the estimation of the nuisance parameter $1 / \mathrm{f}\left(\mathrm{F}^{-1}(\tau)\right)$ (called sparsity) which measures the inverse of the density of the observations around the $\tau$-th quantile. This is usually accomplished based on estimates of the empirical quantile function constructed from residuals of the $\tau$-th quantile regression and using smoothing techniques. See Koenker (1994) for a discussion of the alternative procedures for estimating the sparsity.

An alternative approach to inference that takes advantage of the quantile regression formulation can be based on rank tests. These tests are robust to outliers in $Y$ and are asymptotically distribution 
free since they do not require the estimation of nuisance parameters depending on the error distribution. They are not more complicated to compute than those based on estimation of the sparsity. The theory of tests of linear hypotheses based on ranks has been established by Guttenbrunner, Jureckova, Koenker and Portnoy (1993, GJKP hereafter) and since we do not attempt to summarize the theory of such tests here we refer to GJKP and Koenker (1994) for a review. Let $X=\left[1: X_{1}: X_{2}\right]$ and suppose we are interested in testing the linear hypothesis $\mathrm{H}_{0}: \beta_{2}=0$ vs $\mathrm{H}_{0}: \beta_{2} \neq 0$. The following statistic proposed by GJKP (1993):

$$
\mathrm{W}=\left(\mathrm{Y}_{\mathrm{r}}^{\prime} \mathrm{M} \mathrm{X} \mathrm{X}_{2}\left(\mathrm{X}_{2}^{\prime} \mathrm{M} \mathrm{X}_{2}\right)^{-1} \mathrm{X}_{2}^{\prime} \mathrm{M} \mathrm{Y}_{\mathrm{r}}\right) / \mathrm{A}
$$

where $Y_{r}$ is an estimated vector of ranks of the observations, $M=I-X_{1}\left(X_{1}^{\prime} X_{1}\right)^{-1} X_{1}^{\prime}$ and A is a quantity that does not depend on the distribution of the errors. Visual inspection suggests that the rankbased test is very similar to Lagrange multiplier tests where the y's play the role of the square residuals. This statistic has an asymptotic $\chi^{2}$ (q) distribution under the null hypothesis. The key ingredient in this procedure is the estimation of the ranks vector, which can be obtained as a byproduct of the computation of the regression quantiles for the linear model under the restricted model. Based on the well known duality between hypothesis testing and construction of confidence intervals, a test to evaluate the significance of a single variable can be inverted to obtain a confidence interval for each coefficient. Koenker (1994) discusses in detail computational and theoretical advantages as well as montecarlo results in favor of these tests. In this paper we used this approach to construct confidence intervals for the vector of quantile regression coefficients obtained in the Non-IV models.

We are also interested in testing whether the slope parameters of different conditional quantile functions are significantly different. A simple test based on (17) proceeds by testing whether pairs of slope coefficients are equal at two different quantiles. Suppose we want to test whether the $k$-th slope coefficient is equal at two different quantiles. This corresponds to estimating the model for $m=2$ quantiles and computing the statistic (17) setting $h=0$ and $H$ equal to a ( $1 \times 2 p)$ matrix with one in the $k$-th position, minus one in the $(k+p)$-th position and zero elsewhere. Koenker and Bassett (1982) show that such a test is essentially a test for heteroscedasticity where, under the alternative hypothesis, the conditional variance of $u$ is a linear function of the $k$-th explanatory variable. The test is robust in the sense that no parametric assumptions are made on the distribution of the error term of the model. This is the test procedure we use in the paper to test formally for the presence of heterogeneity in the returns to education.

Nevertheless, it has been well documented (e.g., Buchinsky, 1995) that the "sparsity" estimation approach typically yields downward biased estimates of standard errors. Bootstrap methods have proven to work better in these contexts, particularly the variant in which both $X$ and $Y$ are resampled simultaneously to accommodate heterogeneity in the distribution of the regression errors. Specifically, 
the sample of observations on $(Y, X)$ and the $\tau$ th quantile regression estimator $b_{t}$ are treated as the population and the population coefficient vector, and $B$ random samples are drawn with replacement from the $(Y, X)$ of equal size as the original sample. An estimator $\mathrm{b}_{\tau \mathrm{j}}^{*}, j=1,2, \ldots, B$ is computed for each of these samples. An estimate of $\Omega$ for the given $\tau$ in (16) that is valid when the $u_{i}$ are not iid (conditional on $X$ ) is then:

$$
\hat{\Omega}_{\tau}=\frac{n}{B} \sum_{j=1}^{B}\left(b_{\tau j}^{*}-b_{\tau}\right)\left(b_{\tau j}^{*}-b_{\tau}\right)^{\prime}
$$

Although bootstrap estimators of second moments have not been shown to be consistent, the method does seem to work well in practice (Buchinsky, 1995). An alternative approach is to construct estimates of the standard errors of $b_{t}$ and tests of equality of quantile slope coefficients based on boostrap estimators of percentiles which have been shown to be consistent. We use both approaches in the paper to carry all the tests of heterogeneity and they yield very similar results. All bootstrap simulations are based on 500 repetitions.

\section{Instrumental Variables Quantile Regression}

As in the OLS case, when some of the explanatory variables are determined simultaneously with the response variable, a bias arises due to the existing dependence between the regressors and the error term. Following Powell (1983), the data might be viewed as being generated by the following structural equation:

$$
\mathrm{Y}=\mathrm{Y}_{1} \gamma+\mathrm{X}_{1} \beta+u
$$

Using the terminology familiar from the simultaneous equations literature, $\mathrm{Y}$ is the response variable, $\mathrm{Y}_{1}$ is a $\mathrm{n} \times \mathrm{g}$ matrix of endogenous variables determined simultaneously with $\mathrm{Y}, \gamma$ is the vector of associated coefficients and $\mathrm{X}_{\mathrm{I}}$ is a $\mathrm{n} \times \mathrm{k}$ matrix of exogenous (predetermined) regressors. The simultaneity of $\mathrm{Y}$ and $\mathrm{Y}_{1}$ induces a bias in both OLS and RQ estimators. Assuming that there is a set of $\mathrm{k}_{2}$ instrumental variables collected in the matrix $\mathrm{X}_{2}$, this estimator can be given a two-stage interpretation analogous to Theil's classical interpretation of the Two-Stages Least Squares estimator. In the first stage we project the explanatory variables on the space spanned by the instruments which are, by assumption, uncorrelated with the error term. The second stage performs quantile regression of the response variable on the projections obtained in the previous stage. Thus, the Two-Stage Quantile Regression Estimator is defined as any vector $\xi_{\tau}$ that solves (13) for the model specified in (18) where $\mathrm{Y}_{1}$ is replaced by its first stage OLS projection on the matrix of exogenous variables (including the instruments).

The large-sample properties of this estimator were established by Chen (1988) extending Corollary 3.1 in Powell (1983). Consider the following models: 


$$
\mathrm{Y}=\mathrm{X} \Pi_{1}+V
$$

and

$$
\mathrm{Y}_{1}=\mathrm{X} \Pi+v
$$

where $X=\left[X_{1}, X_{2}\right]$ is a $n x\left(k_{1}+k_{2}\right)$ matrix collecting all the exogenous variables. Equations (19)-(20) are, respectively, reduced forms of the variables $\mathrm{Y}_{1}$ and $\mathrm{Y}$, while $V$ and $v$ are vectors of i.i.d. error terms.

Under some regularity conditions, the asymptotic distribution of the two-stage regression quantile estimator, based on Chen (1988) and Corollary 3.1 of Powell (1983), is given by the following result (Also, see Ribeiro (1996)):

$$
\begin{aligned}
& \sqrt{\mathrm{n}}\left(\xi^{*} \tau^{-} \xi_{\tau}\right) \rightarrow \mathrm{N}\left(0, \mathrm{C} \mathrm{Q}^{-1}\right) \\
& \mathrm{C}=\mathrm{E}\left[\mathrm{f}\left(\mathrm{F}^{-1}(\tau)\right)^{-1} \varphi_{\tau}\left(v_{i}\right)-V_{i} \gamma\right]^{-1}
\end{aligned}
$$

where $\mathrm{Q}=\operatorname{plim} \mathrm{n}^{-1}\left(\mathrm{Z}^{\prime} \mathrm{Z}\right)$ with $\mathrm{Z}=\left(\mathrm{X} \Pi_{1}, \mathrm{X}_{1}\right), \varphi_{\tau}\left(v_{i}\right)=\tau-\mathrm{I}\left(v_{i}<0\right)$ is the $\tau$-quantile score function, $\mathrm{F}$ and $\mathrm{f}$ are the distribution and density functions of $\mathrm{v}_{\mathrm{i}}$, the residuals from the first stage projection of $\mathrm{Y}$ on the matrix of exogenous variables.

In practice $Q$ is estimated by $n^{-1}\left(Z^{*} Z\right)$ with $Z^{*}=\left(X \Pi^{*}{ }_{1}, X_{1}\right)$ and $\Pi^{*}{ }_{1}$ is the OLS estimate of $\Pi_{1}$ in equation (19), $v_{i}$ and $V_{i}$ are replaced by the residuals of the least squares fit of equations (19) and (20) respectively, with $u_{i}=v_{i}-V_{i} \gamma$, and $\gamma$ is replaced by its (consistent) quantile regression estimate obtained from equation (18) in the second stage of the estimation process. The expectation term is estimated by its sample analogue. This also requires the estimation of the sparsity function which is carried out using non-parametric smoothing techniques. The test for heterogeneity in this context are also based on the suitable variation of the $X-Y$ version of the bootstrap for the same reasons indicated above. 